\title{
Las excavaciones de Gabriel Llabrés, Rafael Isasi y Juan Llabrés en la ciudad romana de Pollentia (Alcudia, Mallorca) (1923-1946) \\ The excavations of Gabriel Llabrés, Rafael Isasi and Juan Llabrés at the Roman city of Pollentia (Alcùdia, Mallorca) (1923-1946)
}

\author{
Bartomeu Vallori Márquez \\ Universitat de Barcelona (ERAAUB) \\ Margarita Orfila Pons \\ Universidad de Granada \\ Miguel Ángel Cau Ontiveros \\ (ICREA) / (ERAAUB)
}

\begin{abstract}
RESUMEN
La tradición arqueológica en la ciudad romana de Pollentia (Alcudia, Mallorca) se remonta a la intervención de G. Llabrés y R. Isasi en 1923. Sus trabajos se prolongaron con cierta regularidad hasta 1946 y afectaron a amplias zonas realizando hallazgos destacables. En este artículo, se presenta el resultado de la consulta de documentación inédita acerca de estas intervenciones. Esto ha permitido reconstruir las campañas de excavación, especialmente las de 1942 a 1946, muy poco conocidas hasta ahora, y situarlas en la planta general del yacimiento, lo que supone un avance significativo en el conocimiento topográfico de esta ciudad romana de provincias.
\end{abstract}

\section{SUMMARY}

Archaeological research in the Roman city of Pollentia (Alcúdia, Mallorca) began in 1923 with the excavations of G. Llabrés and R. Isasi. From 1923 to 1946, their fieldwork affected large areas of the city and important remains were uncovered. In this article, the results of the revision of old documents from these excavations are presented. In short, this work has allowed the reconstruction of the fieldwork campaigns, particularly those carried out between 1942 and 1946, and also their location in the general plan of the site. All together this represents a remarkable advance in the knowledge of the topography in this provincial Roman city.

PALABRAS CLAVE: Excavaciones arqueológicas, historiografía, arqueología romana, Mallorca, Pollentia.

KEYWORDS: Archaeological Excavations, Historiography, Roman Archaeology, Mallorca, Pollentia.

\section{INTRODUCCIÓN}

La ciudad romana de Pollentia se encuentra en la zona NE de la isla de Mallorca (Figura 1), a las afue-

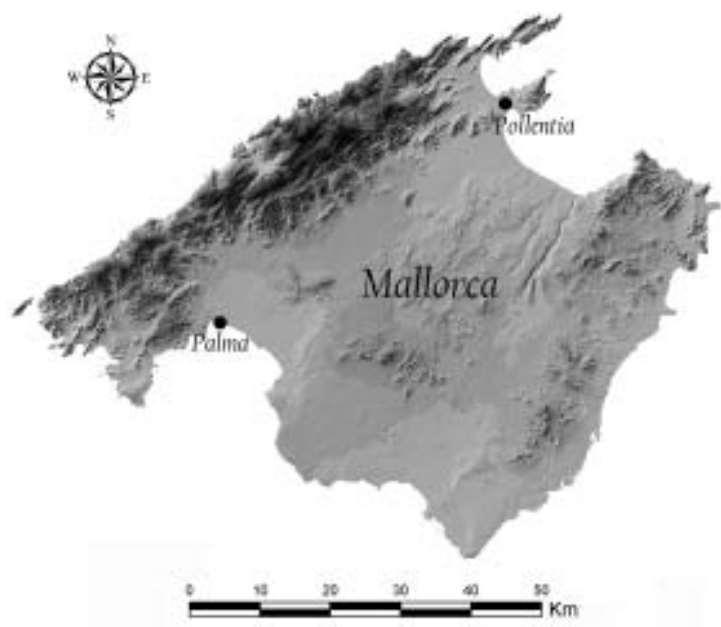

Figura 1. Isla de Mallorca y situación de Pollentia.

ras de la población de Alcudia. Según Estrabón (3.5.2; Blanes et alii 1990), su fundación tuvo lugar después de la conquista de las islas Baleares por parte del cónsul Q. Caecilius Metellus en el año 123 a.C., junto a Palma (actual Palma), aunque las construcciones más antiguas halladas en ambas se fechan entre el 70 y el 60 a.C. En Pollentia, contamos para esta época con la primera estructuración del forum con la insula 01 de tabernae y, seguramente, el templo toscano o Capitolium, aparte de un gran edificio de aparejo almohadillado en el área de sa Portella.

La ciudad se desarrolló urbanísticamente entre los siglos I a.C. y III d.C. En el siglo III d.C. un fuerte in- 
cendio destruyó diferentes partes de la ciudad, siendo sus efectos especialmente visibles en la insula 01 de tabernae al $\mathrm{W}$ del forum, donde el incendio se fecha con precisión hacia el 270-280 d.C. Este episodio comportó cambios importantes en la configuración de la ciudad (Orfila 2000), aunque no supuso su abandono, puesto que continuó habitada durante la Antigüedad Tardía, como demuestra la ocupación del barrio de Sa Portella, en época vándala y bizantina (Gumà, Riera y Torres 1998: 250-251; Orfila et alii 2000:229). En el foro se construyó una fortificación, fechada por el momento con un terminus post quem (t.p.q.) en el tercer cuarto del siglo v d.C., que circundaba el centro de la ciudad (Orfila et alii 2000). Posteriormente, se asentó en el mismo solar del forum una necrópolis (Orfila, Arribas y Cau 1999) de cronología imprecisa. De época islámica, se han documentado, en el área foral, algunas construcciones menores con una cronología final en los siglos X-XI d.C (Orfila y Riera 2002), así como diferentes trincheras de expolio de muros de diversas estructuras anteriores.

Desde los inicios de las excavaciones en 1923, la ciudad romana de Pollentia se ha convertido progresivamente en un yacimiento de referencia en la arqueología hispánica. Entre 1923 y 1955 fue uno de los yacimientos a los que el Ministerio de Bellas Artes concedió subvención para excavar, siendo las primeras excavaciones con carácter oficial de las Baleares (Merino 1995: 40). Los hallazgos, de una cierta importancia, llamaron la atención de la William L. Bryant Foundation, que financió trabajos de excavación en 1946 (Doenges 2005b: 19), y desde 1952 hasta 1995. Durante este período, y gracias a esta financiación, Pollentia se convirtió en un centro de referencia gracias al equipo de excavación, a la aplicación de nuevas metodologías y a la formación de arqueólogos (Mascaró Pasarius 1968: 302-305; Doenges 2005b: 19; Orfila 2007: 91-92).

En realidad, el interés por la antigua ciudad romana de Pollentia de la que hablan las fuentes escritas y cuyo recuerdo se había difuminado, se remonta al siglo XVI, cuando Binimelis (1927: 161), en 1593, propuso que Pollentia podría encontrarse en los campos adyacentes a la ermita Santa Anna, al SE de Alcudia. Durante los siglos posteriores, se sostuvo un intenso debate (Vallori y Cau, próxima aparición) entre los que defendían la hipótesis de Binimelis (Furió 1838; Moragues y Bover 1841) y los que preferían ubicarla en la zona del municipio actual de Pollença, al NW del de Alcudia (Dameto 1632: 3435; Moragues y Bover 1841: 845).

Los hallazgos a lo largo de los siglos XVII-XIX se encargarían de inclinar la balanza a favor de los campos de Alcudia (Vallori y Cau, próxima aparición). En la segunda mitad del XviII, se halló en el Pedret de Bóquer (Pollença) una tabula patronatus ${ }^{1}$ (Serra y Ferragut 1766) de la ciuitas Bocchoritana ${ }^{2}$, la ciudad federada de Bocchor de las fuentes clásicas, lo que confirmaba que en este emplazamiento se alzaba la antigua Bocchor y no Pollentia. Finalmente, en 1887, se halló en Santa Anna la única inscripción que nombra a Pollentia ${ }^{3}$ (Hübner 1888). Una vez ubicados con cierta seguridad los terrenos donde estuvo enclavada la antigua Pollentia, la arqueología del siglo xx tenía por delante un rico yacimiento por explorar. Fue durante los años 20 cuando empezaron las primeras excavaciones con voluntad científica, de la mano de Gabriel Llabrés y Rafael Isasi.

Parte de la documentación de las intervenciones que tuvieron lugar entre 1923 y 1946 fue utilizada por Arribas, Tarradell y Woods (1973) para situar de manera aproximada las áreas de excavación de Llabrés e Isasi y, posteriormente, analizada por Merino para reconstruir las excavaciones de los años 1923, 1926 y 1927 (Merino 1995, 1999).

En esta contribución, ofrecemos el resultado de la consulta de una serie de volúmenes inéditos elaborados por Isasi, codirector de los trabajos y de los diarios de excavación, puestos recientemente a disposición pública por su familia (Isasi y Llabrés 1933, 1934, 1935; Isasi s.d.-a, s.d.-b, s.d.-c, s.d.-d, s.d.-e) y depositados en el Museu de Mallorca. Esto ha permitido reconstruir las sucesivas campañas, situando topográficamente los sectores excavados, gracias a la planimetría elaborada por Isasi y a las indicaciones de los diarios de excavación. Además de varias estructuras, hemos podido ubicar también piezas singulares aparecidas durante estos trabajos, tales como inscripciones o estatuas. El conocimiento de las excavaciones de 1923-1946 tiene un gran valor historiográfico y, además, la localización topográfica de estas intervenciones permite valorar el potencial arqueológico actual de varias zonas del yacimiento. Se definen, de esta manera, algunos sectores de los que tenemos un conocimiento topográfico, pero en los que la estratigrafía antigua ha sido alterada, mientras que otros no se vieron afectados y pueden ofrecer, con más probabilidad, estratigrafías mejor conservadas.

\footnotetext{
${ }^{1}$ Conservada en la Biblioteca Vivot de Palma.

${ }^{2}$ Otra tabula patronatus referente a la ciuitas Bocchorita$n a$ fue hallada en 1951 cerca del Puerto de Pollença (Amorós 1951). Se conserva en el Museu de Mallorca, inventario 28.091 .

${ }^{3}$ CIBal 24 = Veny 1965, 41-42.
} 


\section{LOS PERSONAJES Y LA GÉNESIS DE LAS EXCAVACIONES SISTEMÁTICAS}

Gabriel Llabrés y Quintana (Binissalem, Mallorca, 1858 - Palma, 1928) (Figuras 2 y 6) (Domínguez 1989: 29) empezó en 1880 sus estudios en la Escuela Superior de Diplomática. Ésta había sido creada en 1856, y una de sus funciones era la formación de personal técnico que se encargara del patrimonio nacional fruto de las desamortizaciones del siglo XIX (Peiró y Pasamar 1996: 140, 164-168), protagonizando la creación de la carrera de erudito profesional en detrimento del mundo universitario (Merino 1995: 41; Peiró y Pasamar 1996: 17, 39-40, 125-126, 163-164; Casado 2006: 344-345). A lo largo de su vida, Llabrés desarrolló esta carrera de erudito, desempeñando cargos tanto en las islas Baleares como por toda la Península —destinos como Teruel, Cáceres, Huesca o Santander figuran en su currículo-. Para ello tejió una amplia red de contactos, elemento necesario en la administración canovista (Peiró y Pasamar 1996: 88-93), tanto en el ámbito político - Antonio Maura, Damià Isern- (Peiró 1992: 29-33), como científico-erudito - Fidel Fita, Antonio Elias de Molins, Emil Hübner, Émile Cartailhac, José Ramón Mélida, Francisco Álvarez Ossorio- (Merino 1999: 40-43). Su papel en el mundo erudito se vio favorecido por su relación con la Societat Arqueològica Lul-liana y con su publicación, el Bolletí de la Societat Arqueològica Lul-liana, de la cual fue director en varias ocasiones, y que le permitió ampliar sus contactos (Peiró 1992: 21-25, 63; Merino 1997: 378). Como parte de la carrera erudita, formó parte de academias como la Real Academia de la Historia (1894), o la Academia de Bellas Artes de San Fernando (1900) (Peiró 1992: 26-28). También participó en instituciones como las Comisiones Provinciales de Monumentos, especialmente la Comisión Provincial de Monumentos de las Baleares (desde 1895), cuyos cargos eran dominados por el Cuerpo de Archiveros (Peiró y Pasamar 1996: 141; Merino 1997: 374), y cuya función era la protección del patrimonio histórico-artístico (Merino 1999: 40-43). Una vez volvió definitivamente a Mallorca en 1914, recobró su interés previo por la Antigüedad en la isla ${ }^{4}$ y por la ciudad romana de Pollentia (Peiró 1992: 63), lo que se vería culminado por el inicio de las excavaciones, bajo su dirección, en 1923.

${ }^{4}$ Poco después de que Llabrés retomara la dirección del Bolletí de la Societat Arqueològica Lul-liana, en 1917, se publicó la versión fragmentaria en catalán de la Historia de Mallorca de J. Binimelis, ya mencionada, de 1593.

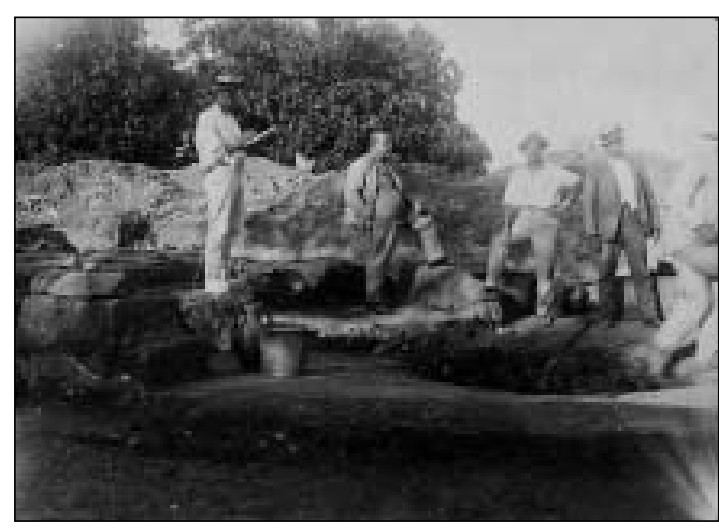

Figura 2. La dirección de las campañas 1923-1927, con algunos personajes locales, en el interior de la habitación C, excavada en 1923. De izquierda a derecha: Rafael Isasi, Pere Ventayol, personaje desconocido, Gabriel Llabrés y personaje desconocido. Foto: Isasi s.d.-d: 83. (C) Museu de Mallorca.

Rafael M.․․ Isasi Ransomé (Fig. 2) (Londres 1863 Palma 1948) fue un militar, apasionado de la historia y la arqueología. Gracias a su profesión y al hecho de estar destinado en Mallorca, pudo recorrer la isla y conocer y documentar numerosos yacimientos. Formó parte de diferentes instituciones culturales, siendo Comisario Insular de Excavaciones ${ }^{5}$ (19411948) (Díaz-Andreu y Ramírez 2001: 330) y director de la Sección Arqueológica del Museo Provincial de Bellas Artes (1936-1948) (Pons 1948; Rosselló Bordoy 1971: 87). Su destreza en el dibujo, junto a la instrucción militar en cartografía y dibujo de paisajes, le permitieron convertirse en el documentalista gráfico de las excavaciones de Pollentia entre 1923 y 1946 (Rosselló Bordoy 1971: 88; Rosselló Bordoy y Merino 2005: 149).

Joan Llabrés (Palencia 1900 - Mallorca 1975) sustituyó a su padre, Gabriel Llabrés, en la dirección de las excavaciones de Pollentia a partir de 1930, después su muerte. En 1928 empezó su carrera en el Cuerpo Técnico General de Gobernación, donde se jubiló en 1970 como Jefe Superior de Administración Civil. Entre los muchos cargos que ejerció, destaca para el tema de este trabajo el de director del $\mathrm{Mu}$ seo Arqueológico de Alcudia, y fue miembro de varias academias, como la Real Academia de la Historia o la Academia de Buenas Letras de Barcelona. Entre su vasta producción bibliográfica, destaca la que dedicó a la historia, especialmente la naval, materia

\footnotetext{
${ }^{5}$ Carta de 14 de mayo de 1941 , en la que se nombra Comisario Insular a R. Isasi. En principio fue nombrado J. Llabrés, pero al no tener residencia permanente en Mallorca, fue sustituido por R. Isasi (Archivo General de la Administración (A.G.A.), caja 219, Topográfico 12//25).
} 
en la que se le considera un verdadero especialista (Pons 1975: 591-592). Desempeñó la dirección de las excavaciones en Pollentia hasta el año 1942, después del cual no parece que participara en las labores de excavación, si bien la documentación es un poco confusa en este sentido.

Una vez que Gabriel Llabrés volvió a Mallorca tras ejercer como profesor de instituto en varias ciudades peninsulares, y dada la importancia del sistema de contactos en la época (Peiró y Pasamar 1996: 88-93), su peso como erudito y su red de relaciones (Peiró 1992: 16, 24-25, 29-33, 63) fueron decisivos para el futuro del yacimiento de Pollentia. Las circunstancias que llevaron a los primeros trabajos arqueológicos no dejan de ser curiosas y un tanto sorprendentes. A principios de los años 20, Ferran Weyler Santacana, hijo del general mallorquín Valeriano Weyler, era el director general de Bellas Artes del Ministerio de Instrucción Pública y Bellas Artes. Gracias a él, se concedieron 5.000 ptas. a la Societat Arqueològica Lul-liana para que las destinara a excavaciones arqueológicas en Mallorca. No obstante, era necesario que el director de las excavaciones fuera miembro de la Academia de la Historia, o de la Real Academia de Bellas Artes de San Fernando, lo que la Societat Arqueològica Lul-liana no cumplía. Se solicitó entonces a la Dirección General de Weyler que se trasladara la subvención a Gabriel Llabrés y a Rafael Isasi, ambos miembros de dichas instituciones. Por otra parte, la subvención debía ser destinada, en principio, al estudio de algún yacimiento talayótico, pero se decidió finalmente dedicarla a excavar en Pollentia. Las expectativas de hallar estructuras monumentales eran mayores en el yacimiento romano, lo que debía facilitar la justificación de la subvención (Sans 1929: 354; Merino 1995: 40-41). En 1923, tuvo lugar la primera campaña de excavación arqueológica con finalidad científica y con permisos oficiales en los terrenos donde se ubicaba la antigua Pollentia (Merino 1995: 40; Rosselló Bordoy y Merino 2005: 148; Orfila 2007: 89).

\section{DOCUMENTACIÓN Y CARACTERÍSTICAS DE LAS EXCAVACIONES}

Como ya hemos indicado, Rafael Isasi era el documentalista de la excavación. Los trabajos de campo son cuidadosamente descritos por éste en los diarios de excavación, hasta el punto de que los podemos seguir casi siempre día a día. Realizó también todo un corpus gráfico, que abarca desde dibujos con cámara clara y al natural, hasta detalladas planimetrías de las estructuras, con todo tipo de indicaciones. La precisión de esta documentación ha permitido situar la mayoría de las intervenciones realizadas entre 1923 y 1946 sobre planimetría actual.

Por otra parte, los resultados de las excavaciones de los años 20 fueron descritos en memorias oficiales que fueron remitidas al Ministerio de Instrucción Pública, aunque, según parece, se perdieron durante la Guerra Civil. Posteriormente, sólo las campañas de 1930-1931 fueron publicadas (Llabrés e Isasi 1934). También algunas publicaciones de carácter más divulgativo aportan alguna información complementaria (Ventayol 1927), que fue utilizada por Bosch (1979-1980) para reconstruir las excavaciones de los años 1930-1943. La documentación almacenada en el Archivo General de la Administración (A.G.A.), en Alcalá de Henares, ofrece alguna información concreta sobre prespuestos y legislación aplicable a las excavaciones y los materiales hallados (A.G.A., cajas 217, 219 y 31/1035). Finalmente, la correspondencia personal de Gabriel Llabrés (Arxiu Municipal de Palma, fondo G. Llabrés, expediente n. 1058) es asimismo crucial para entender estas campañas.

El objetivo principal de los trabajos era, según Llabrés (Llabrés 1923, 1924), definir los límites de la ciudad y sus principales zonas. Los terrenos eran de propiedad privada, por lo que las excavaciones debían realizarse con el acuerdo previo de los propietarios, que no permitían arrancar árboles, ni dejar la excavación abierta. Estas circunstancias obligaban a excavar en zanjas que respetaran las hileras de árboles y que, una vez acabada la excavación, debían ser cubiertas de nuevo. Frecuentemente, los sillares encontrados eran arrancados por los propietarios y, posteriormente, reutilizados o vendidos (Arribas, Orfila y Trias 2000; Doenges 2005a: 4). A consecuencia de esta práctica como veremos, se han documentado expolios modernos de muros en excavaciones recientes (Equip Pollentia 1994: 215).

La excavación se realizaba sin seguir ningún criterio estratigráfico y, naturalmente, sin registro gráfico de la estratigrafía; sólo se conservan en este sentido algunas referencias a niveles de destrucción o vigas carbonizadas, que los directores anotaron en los diarios de excavación (Isasi y Llabrés 1933, 1934, 1935; Llabrés e Isasi 1934). Estos diarios permiten seguir los trabajos prácticamente día a día. Las dataciones se hacían a partir de fuentes históricas, artísticas (especialmente respecto a los mosaicos) y numismáticas, y se identificaban sistemáticamente los niveles de destrucción relacionados con episodios de incendio con una supuesta destrucción vándala, que por otra parte se había convertido en un tópico de la 
historiografía local (Furió 1838: 7, 51-53; Reinés y Ferrer 1863; Martorell y Peña 1879: 164; Llabrés 1923; Ventayol 1927: 32-34; Merino 1999: 48; Vallori y Cau proxima aparición).

Muchas de las zanjas con materiales revueltos que se documentan actualmente en las excavaciones de Pollentia son fruto de esta metodología que, junto con la amplitud y dispersión que tuvieron las excavaciones de los años 20 y 30, condicionó los futuros trabajos arqueológicos en el yacimiento (Arribas, Tarradell y Woods 1973: 18-20; Tarradell 1978: 307-308; Orfila, Arribas y Doenges 2000: 52-53, n.42). Al mismo tiempo que se producían hallazgos espectaculares la mayoría de las estatuas de Pollentia se recuperaron a lo largo de estas campañas-, se destruyó un gran volumen del registro arqueológico, perdiéndose toda referencia estratigráfica y descontextualizando muchos materiales. Aún así, las excavaciones profundizaban muchas veces sólo hasta cierto nivel y, una vez se había descubierto una estructura coherente, se cubrían otra vez las zanjas, sin agotar toda la estratigrafía de la zona. Esto ha posibilitado, por ejemplo, la reexcavación de algunos puntos de la Insula 01 de tabernae del forum, pudiendo documentar estratos fechados desde el siglo i a.C. hasta el III d.C. (Chávez, Orfila y Mancilla 2000a, 2000b).

Las excavaciones fueron financiadas desde sus inicios, como ya hemos indicado, por el Ministerio de Instrucción Pública y Bellas Artes. Según las primeras Reales Órdenes que autorizaban las intervenciones y sus presupuestos, los materiales que se extrajeran debían ser trasladados al Museo Arqueológico Nacional $^{6}$ (M.A.N.). Parece extraño que Llabrés, como director de la excavación y gran defensor del patrimonio insular, permitiera, sin ninguna oposición manifiesta, la salida de estos materiales hacia Madrid. Según Merino (1995), la explicación debe buscarse en la relación de proximidad que tenía con el entonces director del M.A.N., José Ramón Mélida; y, por otra parte, en la precaria situación en la que se encontraba el museo provincial de Palma, ubicado en el edificio de La Llotja ${ }^{7}$. Ya desde un primer momento se alzaron voces contrarias al exilio de los materiales, sobre todo por parte de la prensa y de algunos eruditos locales, como el padre Joan Aguiló Pinya, descubridor de la basílica paleocristiana de Son Peretó

\footnotetext{
${ }^{6}$ Real Orden (R.O.) del 24/XII/1925, Gaceta de Madrid no 358 , donde se autoriza la excavación, y se especifica que los objetos encontrados deben remitirse al M.A.N. (A.G.A., caja 31/1035)

${ }^{7}$ La difícil situación de dicho museo y los problemas para crear un Museo de Antigüedades por parte de la Comisión de Monumentos de Baleares provenían ya de la década de los 70 del siglo XIX (Merino 1997: 372-373).
}

(Manacor). El mundo político y cultural de Mallorca se movilizó para solicitar al Ministerio que los objetos que se hallaran en Pollentia permanecieran en Palma, y para ello la Societat Arqueològica Lul-liana, en la que Gabriel Llabrés tenía un papel importante, la alcaldía de Palma y Fomento del Turismo de Mallorca remitieron sendas cartas en este sentido $^{8}$. Como resultado de la presión que ejercieron, en 1927 se derogó la Real Orden (R.O.) de 24/ XII/1925 que obligaba al traslado de los materiales de Pollentia a Madrid ${ }^{9}$. El M.A.N., no obstante, continuaba conservando su primacía, ya que los directores de la excavación debían remitir, después de cada campaña, un listado de los hallazgos, entre los cuales el director del M.A.N. podía escoger las piezas «que no tengan representación en las colecciones, o completen las series que se conservan en el referido Museo Arqueológico Nacional» para que fueran enviadas a la capital (Merino 1995: 41-43).

Los presupuestos que el Ministerio asignaba a las campañas de excavación podían ascender a las 5.000 ptas. anuales, lo que constituía un presupuesto cuantioso para la época. Una gran parte de esta cantidad se invertía en las dietas de los directores y el traslado y tratamiento del material, hasta el punto que éstos representan cerca del $40 \%$ de los gastos. La mano de obra la constituían jornaleros del pueblo de Alcudia, algunos de los cuales participaron en más de una campaña. Según las necesidades de la excavación, se podía aumentar la plantilla (Isasi y Llabrés 1933, 1934, 1935). Por otra parte, era normal que los directores se ausentaran de los trabajos de campo, ya que en ocasiones en que se encontraban en Palma se les tuvo que avisar de algunos hallazgos (Merino 1999: 48).

\section{LA DIRECCIÓN DE GABRIEL LLABRÉS Y RAFAEL ISASI (1923-1928)}

La campaña de 1923 empezó en la finca de Ca'n Basser sin muchos resultados, por lo que se decidió excavar una zanja en sentido NW-SE en la zona vecina del Camp d'en França (Fig. 3) (Ventayol 1927: 53). Aquí se descubrieron estructuras que se interpretaron como parte de un templo o mansión romana, además de varias sepulturas que podemos relacionar actualmente con la necrópolis que, época tardoanti-

\footnotetext{
${ }^{8}$ Cartas originales en A.G.A., caja 31/1035, ref. 10144-74.

${ }^{9}$ R.O. del 17/VI/1927, Gaceta de Madrid no 168 . En esta R.O. detectamos un error respecto a la R.O. que se pretende anular, que es la de 24/XII/1925 y no la de 21/XII/1925 como aparece en el texto redactado de la R.O. del 17/VI/1927.
} 


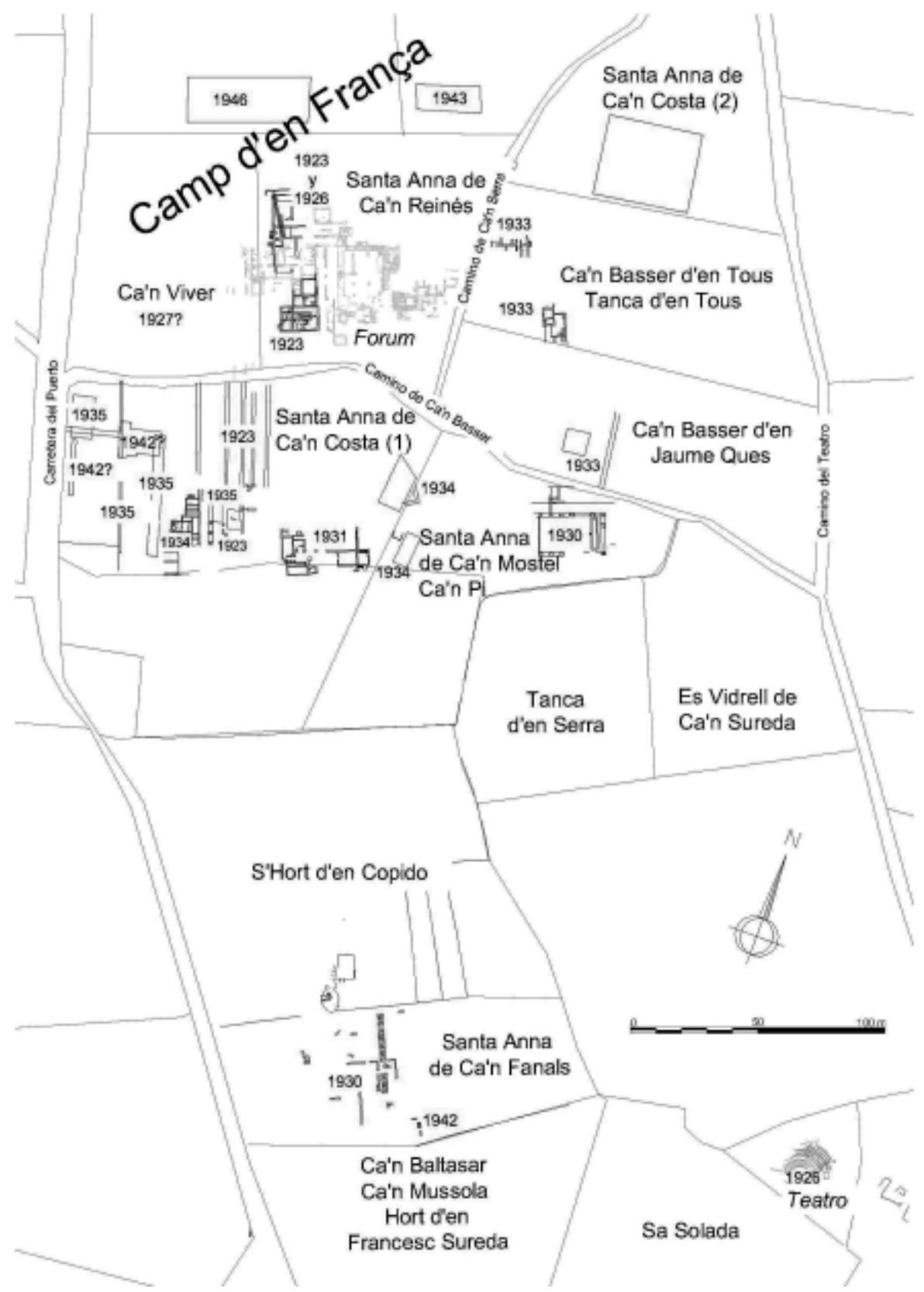

Figura 3. Situación de las excavaciones Llabrés-Isasi en Pollentia desde 1923 hasta 1946.

gua o altomedieval, se asentó sobre el antiguo forum de la ciudad (Merino 1999: 44). Aunque no contamos con croquis ni plano de estos trabajos, sí que disponemos de los de la excavación de 1926 (Llabrés e Isasi 1934), que prosiguió con esta zanja. Estos restos se ubican en la parte $\mathrm{N}$ de la finca Ca'n Reinés dentro de la zona del Camp d'en França (Fig. 3).

Posteriormente, realizaron dos zanjas perpendicu- lares más al S, dentro de la misma parcela. En esos momentos se identificaron dos edificios que fueron llamados Casa del Escultor, con impluuium y pavimentos de mosaico blanco, donde se encontraron numerosos fragmentos de mármol, y Casa del Pintor, donde se encontró cerámica con restos de cal (Llabrés e Isasi 1934; Merino 1999: 44-45). En el plano levantado por Isasi (Isasi s.d.-d) se aprecian 


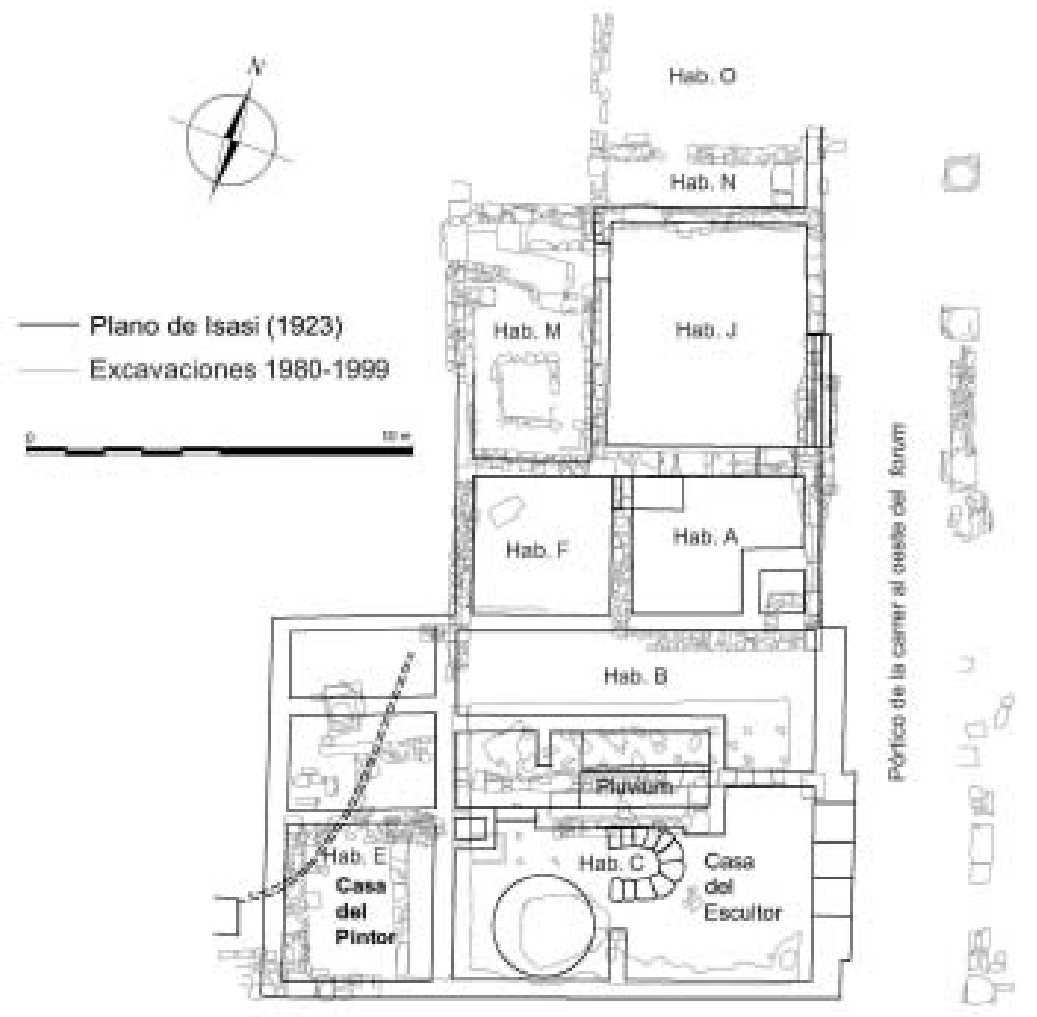

Figura 4. Plano de la excavación de 1923 superpuesto al plano actual del ángulo SE de la Insula 01. Fuente: Isasi s.d.-d, modificado con superposición a la cartografia moderna.

varias habitaciones que siguen, aparentemente, una fachada situada al E. Estas estructuras y las que se excavaron a lo largo de los años 80 en la Insula 01 de tabernae coinciden hasta el punto de poder superponer ambas planimetrías (Fig. 4). La zona excavada en 1923 corresponde, pues, a las habitaciones J, M, A, F, B, C, E y algunas estructuras al W de éstas, en el interior de la Insula 01 . El plano de Isasi documenta, además, una circunferencia en el ángulo SW de la habitación $\mathrm{C}$ o «Casa del Escultor», sin especificar de qué se trata. Nosotros lo identificamos con el pozo D-18, excavado en 1986-1987 (Equip d'excavació de Pollentia 1993: 227). Éste fue identificado porque el opus signinum que lo amortizaba —el «mosaico blanco» al que Llabrés e Isasi hacen referencia - había cedido debido a la inestabilidad del subsuelo. La pequeña depresión creada en el pavimento debió ser lo que encontraron Llabrés e Isasi en 1923 y que representaron con una circunferencia. Por otra parte, ya hemos comentado cómo muchas veces los propietarios de las fincas arrancaban los sillares de las estructuras descubiertas, lo que parece que sucedió con los muros E (fachada) y S de la habitación $\mathrm{C}$, desaparecidos actualmente, pero que aparecen en el plano de 1923. La identificación de estas estructuras permite completar, si bien esquemáticamente, la planta de esta habitación. Algunas fotografías (Figs. 2 y 5) y croquis (Fig. 4) conservados entre la documentación de Isasi confirman esta correspondencia (Isasi s.d.-d: 96).

En este mismo año (1923), todavía se exploraría la finca de Santa Anna de Ca'n Costa, más al S. En la zona central, en la era de estos terrenos, se abrieron cinco zanjas de $\mathrm{N}$ a $\mathrm{S}$, llegando al camino que limita la propiedad por el N. Apareció un edificio con una habitación pavimentada con un gran mosaico ${ }^{10}$, con un pasadizo al SW también con mosaico, y al W un impluuium columnado, donde se descubrieron los restos de una estatua ecuestre de bronce ${ }^{11}$ (Figura 6). Éstos consisten en la cabeza, de $50 \mathrm{~cm}$ de altura y con decoración de varias deidades, y algunas patas del caballo (Ventayol 1927: 53-55; Arribas, Tarradell y Woods 1973: 18-19; Pozo 1989: 78-82; Merino

\footnotetext{
${ }^{10}$ Se conserva en el Museu de Mallorca.

${ }^{11}$ Se conserva en el M.A.N., inventario 1.925/50/1.
} 


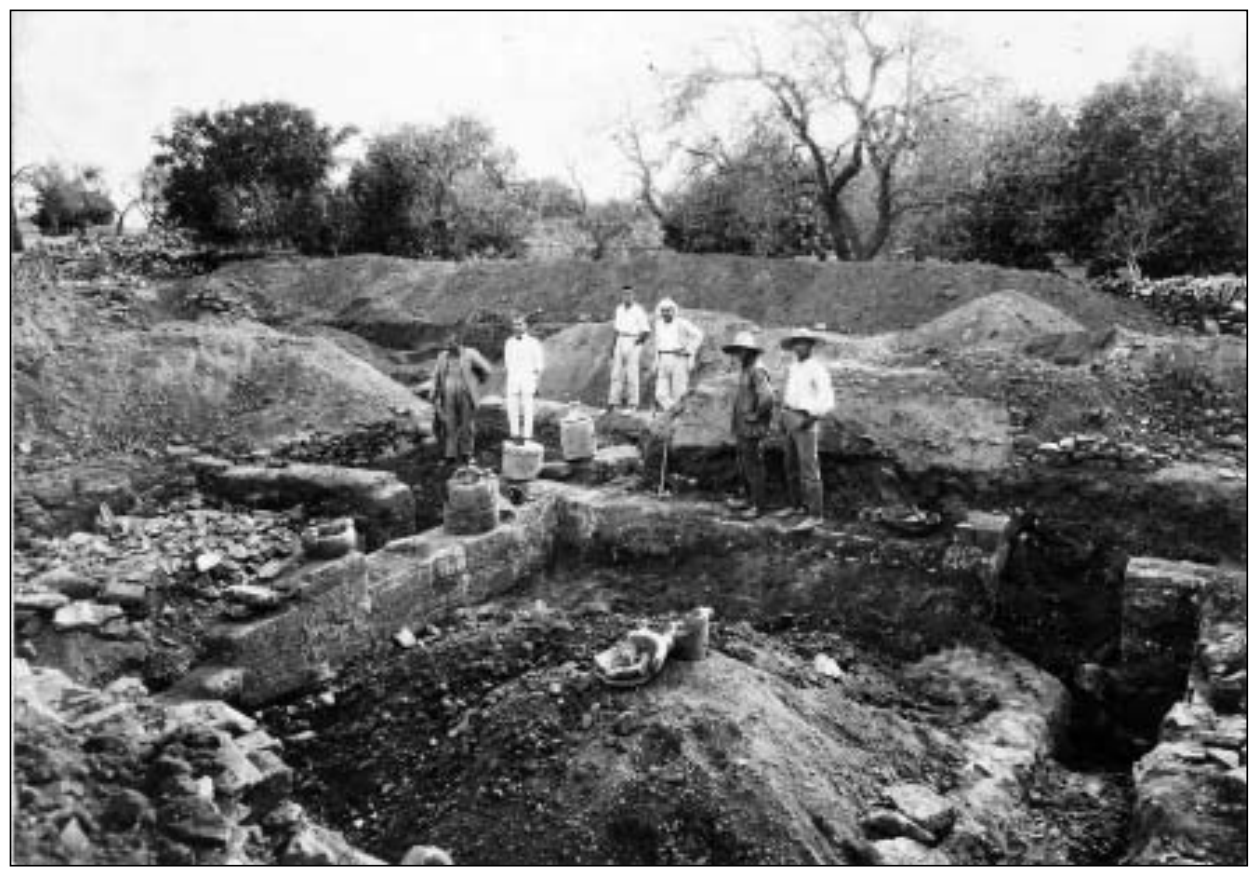

Figura 5. Segunda excavación en Ca'n Reinés (1923), donde se pueden apreciar las habitaciones llamadas actualmente F, A y J. Foto: Isasi s.d.-d: 137. (C) Museu de Mallorca.

1999: 44-46). La pieza se fecha en el siglo I d.C. y debió representar a algún emperador, aunque no se ha descartado — en nuestra opinión de forma más improbable - que pudiera tratarse de un miembro de la aristocracia local (Orfila, Chávez y Cau 2008: 330). Por la información del plano conservado y las referencias de los diarios de campañas posteriores (años 1934-1935), que tomaron como referencia esta excavación, podemos situar este edificio en la parte SE de la era, la parte más elevada de la finca, sobre un muro de contención de tierras. La especial visibilidad sobre la bahía de Alcudia y la suntuosidad de los hallazgos llevaron a Llabrés e Isasi a referirse a este edificio como Casa del Gobernador y Casa del Pretorio, alternativamente (Llabrés 1923, 1924; Isasi y Llabrés 1934). Posteriormente (1934, 1935), se excavaron zanjas en zonas adyacentes para intentar completar la planta (Isasi y Llabrés 1934).

La falta de financiación no permitió reemprender los trabajos de campo hasta 1926, nuevamente en el Camp d'en França, y siguiendo el supuesto templo descubierto parcialmente en 1923 (Ventayol 1927: 56). Las referencias topográficas del plano del área excavada permiten situar la excavación en la mitad norte de la parcela de Ca'n Reinés (Figs. 3 y 7). Se descubrió un muro principal en sentido N-S, al que se adosaban varios al E perpendicularmente, aunque es difícil delimitar habitaciones debido a que la zona

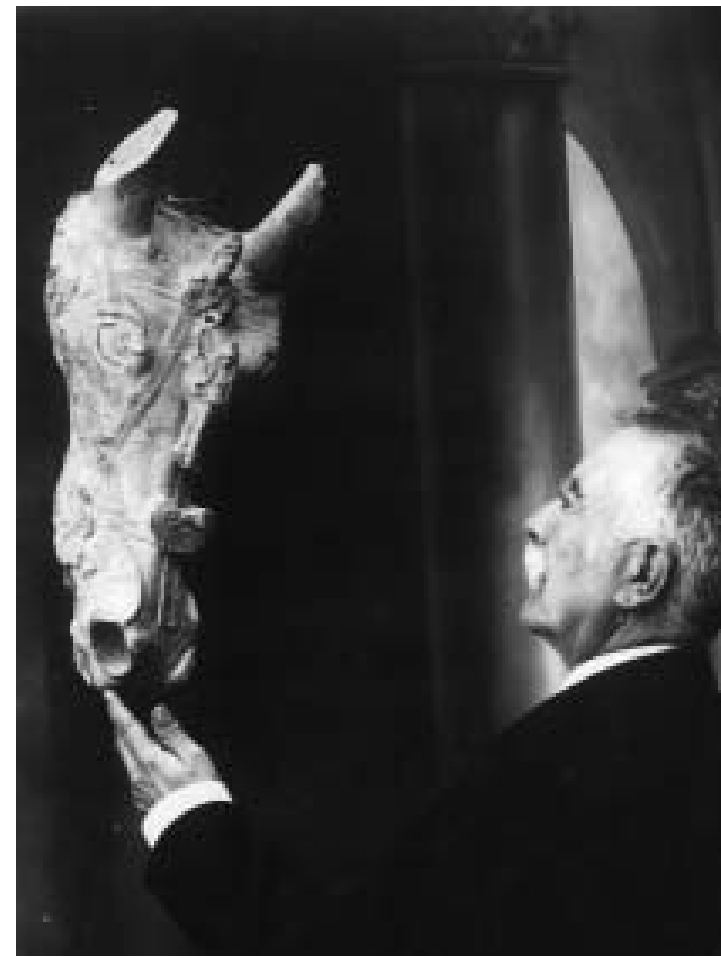

Figura 6. Gabriel Llabrés junto a la cabeza de caballo de bronce descubierta en 1923 en la Casa del Gobernador en Santa Anna de Ca'n Costa. Foto: Museu de Mallorca, en Rosselló Bordoy y Merino, 2005: 144. () Museu de Mallorca. 


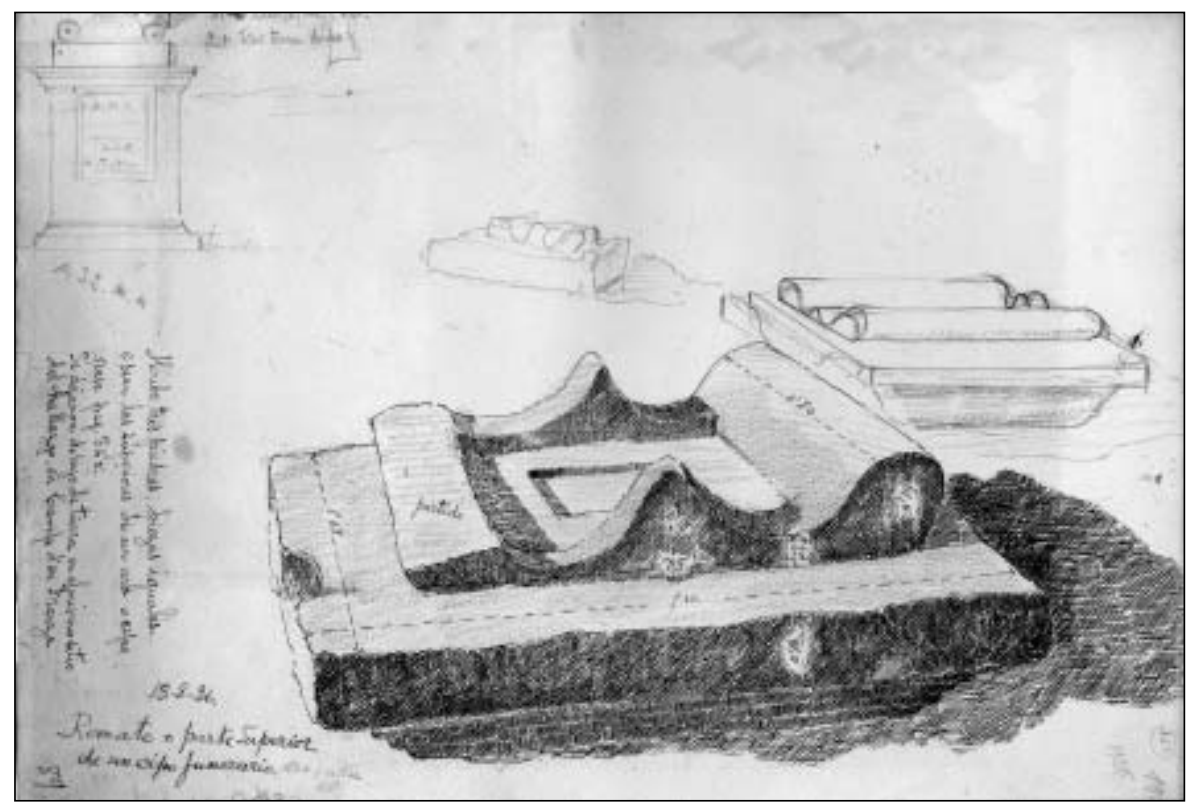

Figura 7. Las tres arce halladas en la excavación de 1926 en el área del templo. Isasi s.d.-d. (C) Museu de Mallorca.

abierta fue reducida. Al W se hallaron tres basamentos moldurados de pedestales. Se excavó también un pozo (Arribas, Tarradell y Woods 1973: 19), actualmente en uso, situado al $\mathrm{N}$ del muro $\mathrm{N}-\mathrm{S}$, donde apareció un probable fragmento de fasti (Mayer, 2008: 93) ${ }^{12}$. No contamos con mucha información sobre elementos estructurales, pero sí de los objetos hallados remitidos al M.A.N. (Ventayol 1927: 56; Merino 1999: 4647): una estatua de Apolo $^{13}$, una identificada como Cautes $^{14}$, el mencionado fragmento de fasti (CIBal 57=Veny, 1965:69-70; Mayer, 2005: 46; 2008), hallado dentro del pozo; un estandarte ${ }^{15}$, atribuido posteriormente (Álvarez Ossorio, 1929; Arce 1984) a un collegium iuuenum. Además se encontraron tres aras, que fueron dejadas in situ (Figura 7) (IsAsI, s.d.-d). El plano conservado se complementa perfectamente con la documentación fotográfica que aparece en algunas publicaciones (Arribas, Tarradell y Woods 1973: láminas 4 y 5a; Isasi s.d.-d). Durante la campaña, se eliminó un muro de piedra seca que atravesaba la cauea del teatro en sentido E-W (Figura 3) (Amorós 1958: 4; Isasi s.d.-d). El hallazgo de elemen-

\footnotetext{
${ }^{12}$ [...]Aprilis [...] Cartago capta fuit $($ CIBal $57=$ Veny 1965, 69-70; Mayer, 2005: 46). Esta pieza se encuentra hoy en día desaparecida.

${ }^{13}$ Conservada en el M.A.N., inventario 33.140.

${ }^{14}$ Conservada en el M.A.N., inventario 33.145. Posteriormente ha sido identificada con una representación de Telesforo (Perea 1997).

${ }^{15}$ Conservado en el M.A.N., inventario 1927/64/7.
}

tos como la inscripción que ha sido relacionada con unos fasti, el estandarte y las tres aras, aunque pueden estar descontextualizados, plantea la posibilidad de que esta zona, al $\mathrm{N}$ del forum, fuera de carácter público, y que se emplazara aquí la sede de alguna institución (collegium) y, como Llabrés e Isasi proponían, algún templo o recinto religioso.

La campaña de 1927 se centró en una parcela dentro de la zona del Camp d'en França, cuya ubicación es en cierto modo problemática, ya que las referencias no son unánimes ${ }^{16}$. Probablemente, se trata de la finca de Ca'n Viver (Fig. 3). Se descubrió la base de una torre circular de 6,70 m de diámetro y grandes sillares, que podría corresponder a una estructura defensiva (Arribas, Tarradell y Woods 1973: 19; Merino 1999: 47; Orfila et alii 2000: 233; Orfila y Arribas 2000: 41), o a algún tipo de estructura monumental o funeraria (Arribas, Tarradell y Woods 1973: 19). También apareció en la zona un aljibe de grandes dimensiones con bóveda. Entre la cultura material hallada destaca una estatua funeraria de tipo pudicitia $^{17}$ (Ventayol 1927: 56; Arribas, Tarradell y Woods 1973: 19; Veny 2005: 142; Moreno 2007: 91; Orfila 2007: 89; Orfila, Chávez y Cau 2008: 330-331).

\footnotetext{
${ }^{16}$ Mientras según Ventayol (1927) la finca era propiedad de Francisca Ventayol, según la prensa era de Francesc Viver (Merino 1999).

${ }^{17}$ Conservada en el Museu de Mallorca - Museu Monogràfic de Pol-lèntia, inventario 21.719.
} 
Podemos extraer de una de las pocas publicaciones de Llabrés (1924) sobre Pollentia, que a lo largo de los años 20 excavaron en la zona de Mar i Estany, situada en la restinga de la Albufera de Alcudia, cerca del teatro romano y del mar. La breve descripción que hace Llabrés es la de una serie de construcciones pobres, y una explanada de cantos con argamasa donde aparecieron tablas de pizarra, a la que llama «plaza del mercado». Bautiza la zona como «el arrabal» o «barrio portuario»; posteriormente, en 1930, Juan Llabrés y Rafael Isasi retomarían puntualmente los trabajos en esta zona.

\section{LA DIRECCIÓN DE JUAN LLABRÉS Y RAFAEL ISASI (1930-1936)}

Después de la muerte de Gabriel Llabrés en 1928, se incorporó a la dirección de las excavaciones su hijo Juan Llabrés Bernal, junto a Rafael Isasi. La primera campaña de la nueva etapa tuvo lugar en el verano de 1930 en la finca de Santa Anna de Ca'n Fanals (Fig. 3), cerca del mar, donde se descubrió un edificio rectangular de 19 × $7 \mathrm{~m}$, orientado E-W, y un conjunto de 38 tumbas, orientadas en sentido E$\mathrm{W}$, que atravesaban el edificio. Entre las tumbas se podían diferenciar varios tipos: de ataúd (o cista), de huesera y las construidas con losas. Se sugirió que el edificio hubiera sido una basílica cristiana. Excavaron también un pozo, donde se halló una cabeza de mármol de niña adolescente, así como una terracota arquitectónica representando a dos leones, que seguramente corresponde a una cornisa con desagüie ${ }^{18}$ (Llabrés e Isasi 1934: 3-7; Arribas, Tarradell y Woods 1973: 19-20; Bosch 1979-1980: 378-379).

Después de esta intervención, los trabajos se dirigieron a la parte $\mathrm{N}$ de la finca de Ca'n Pi (también llamada Santa Anna de Ca'n Mostel o simplemente Ca'n Mostel), limitando por el $\mathrm{N}$ con el camino vecinal de Ca'n Bassé (Figs. 3 y 8). Se descubrió un edificio rectangular de $29 \mathrm{~m}$ de longitud total, con un peristylum columnado ( 11 bases de columna en un lado) de 27 x $16 \mathrm{~m}$. Una canal de piedra bordeaba la columnata y daba a un depósito en el lado E del patio (Fig. 8). Al N, al lado del camino, aparecieron varias estancias que fueron llamadas C, D y E (Llabrés e Isasi 1934: 7-0; Arribas, Tarradell y Woods

${ }^{18}$ Posteriormente, excavaron en la zona Rafael Isasi, en una breve intervención (1943) (Figura 3) (Bosch, 1979-1980: 378-379), y Martín Almagro y Lluís R. Amorós (1949-1950), descubriendo otros sectores de la necrópolis (Almagro y Amorós 1953-54: 238-240; Arribas, Tarradell y Woods 1973: 19-20).
1973: 20; Bosch 1979-1980: 379-380). Los intercolumnios miden unos $2,70 \mathrm{~m}$ mientras que el deambulacro del peristylum $4 \mathrm{~m}$ de ancho, y la parte interior mide $13 \mathrm{~m} \mathrm{~N}-\mathrm{S}$ y al menos $24 \mathrm{E}-\mathrm{W}$. Estas magnitudes nos inclinan a pensar que se trata de algún tipo de estructura pública, quizás una plaza pública o la palaestra de unas termas, de manera parecida a las termas del foro de Herculaneum o las del foro de Pompeii (Nielsen 1990).

En el mismo año, se realizó un sondeo en la finca de Ca'n Jaqués, al S del teatro, siguiendo los trabajos de los años 20 en esta zona, que fue denominada arrabal portuario. El objetivo era localizar el barrio portuario de la ciudad, aunque los resultados fueron un tanto decepcionantes, ya que sólo aparecieron fragmentos de ánfora, removidos, según Llabrés e Isasi, por las obras de desecación que se habían llevado a cabo en la Albufera cincuenta años atrás.

En 1931, excavaron en la finca de Santa Anna de Ca'n Costa, en una zona próxima a la explorada en 1923 (Figura 3). Hallaron los restos de un edificio con una posible fachada con dos columnas y un amplio vestíbulo, que daba a una calle al E (Figuras 9 y 10). Al W de estas estructuras descubrieron, además, un horno con fragmentos de ánforas y un conjunto de dependencias y patios que interpretaron como un alfar (Fig. 9). El conjunto fue llamado Casa del Colonizador (Llabrés e Isasi 1934: 10-17; Arribas, Tarradell y Woods 1973: 20; Bosch 1979-1980: 380; Orfila y Arribas 2000: 33 34). Las memorias de excavación interpretan la parte E del edificio como una fachada con dos columnas, y con una canalización que cruza el edificio en sentido N-S (Isasi s.d.-d). No obstante, a la luz de los hallazgos de las últimas décadas en el forum (Orfila, Arribas y Cau 1999: 104-107, 109-112; Orfila, Arribas y Doenges 2000: 59), la supuesta canal podría corresponder en realidad una serie de umbrales con ranuras, que servirían para encajar tablones para cerrar las entradas a una serie de tabernae, mientras que las dos columnas corresponderían a una línea de pórtico delante de la fachada (Figs. 9 y 10).

En 1933, los excavadores eligieron las dos parcelas de Ca'n Basser de Tous y de Jaume Ques (Fig. 3) (Bosch 1979-1980: 380). Se abrieron en una primera fase dos zanjas en la finca de Ques, una en la parte W, cerca del camino de Ca'n Serra, de la que casi no tenemos información, y otra más al E, y que venía a continuar los trabajos realizados en 1930 en la vecina finca de $\mathrm{Ca}$ 'n $\mathrm{Pi}$, donde se encontró el gran edificio con peristylum ya mencionado. Del croquis que se dibujó, podemos extraer que la excavación no tuvo tanta amplitud como la de Ca'n Pi y no permitió delimitar muchas estructuras. En una de las zan- 


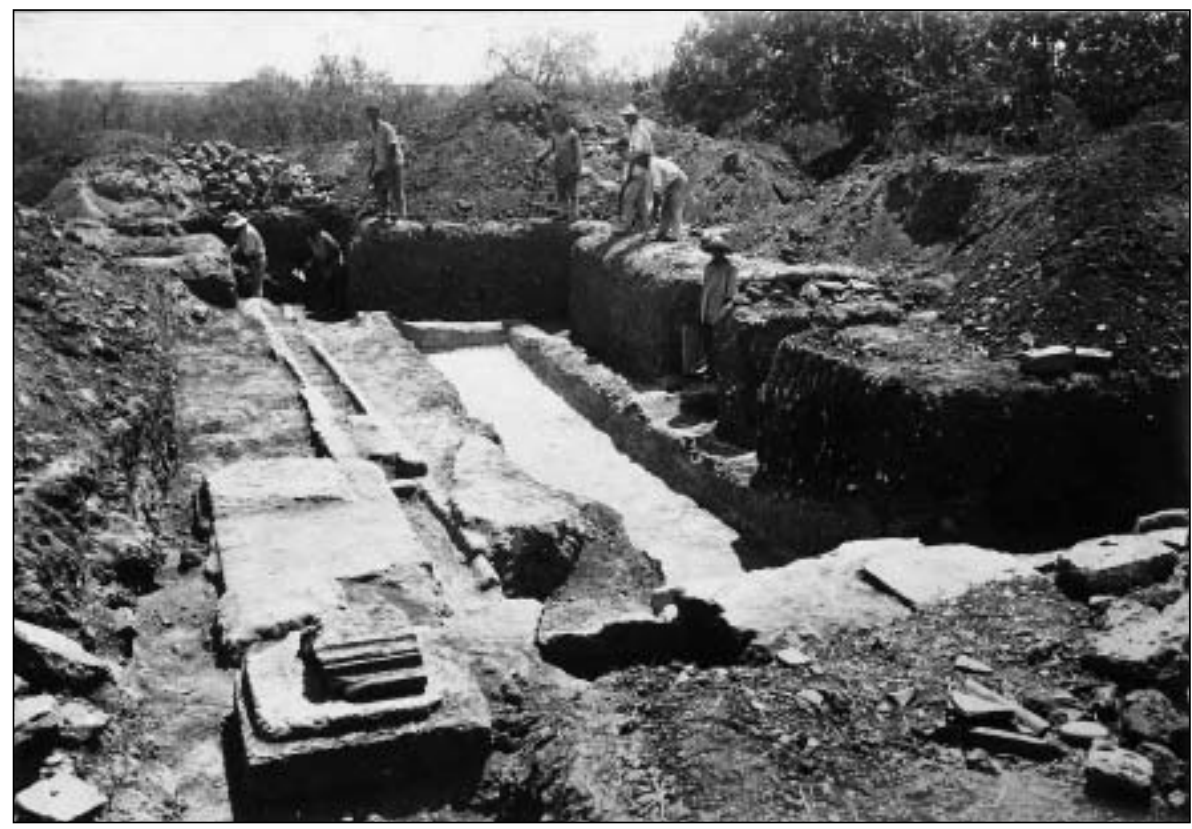

Figura 8. Excavación de 1930 en Ca'n Pi. Lado E del peristylium. Foto: Isasi s.d.-d. (C) Museu de Mallorca.

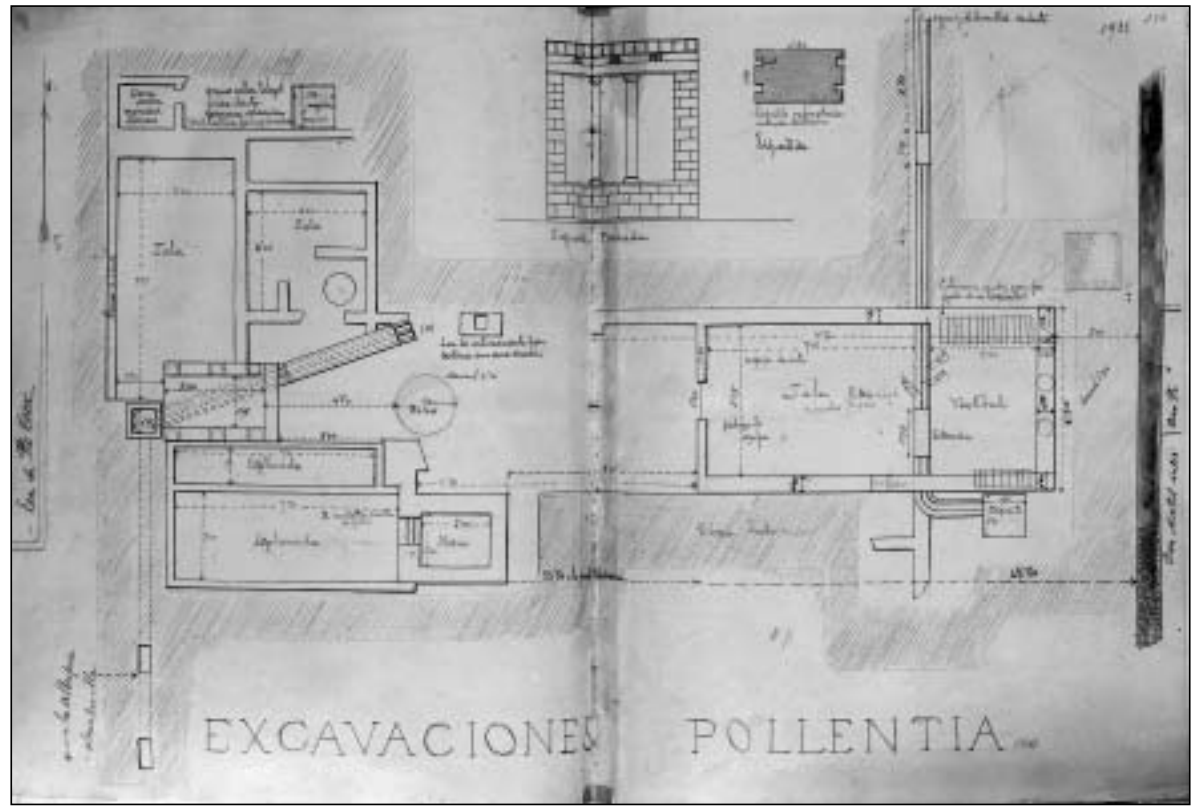

Figura 9. Planta de la Casa del Colonizador en Santa Anna de Ca'n Costa (1931). Foto: Isasi, s.d.-d. @ Museu de Mallorca.

jas, se encontraron dos muros paralelos en sentido E$\mathrm{W}$, separados $6,60 \mathrm{~m}$, y que interpretaron como un lienzo de muralla, aunque la información con la que contamos no es suficiente como para situar con un mínimo de precisión la estructura. Según la descrip- ción que proporcionan Isasi y Llabrés (Isasi y Llabrés 1933), sin embargo, esta muralla sería parecida a los restos de la fortificación tardía hallada en el forum a lo largo de las excavaciones modernas (Orfila et alii 2000: 231-233; Riera, Cau y Orfila 2000). 


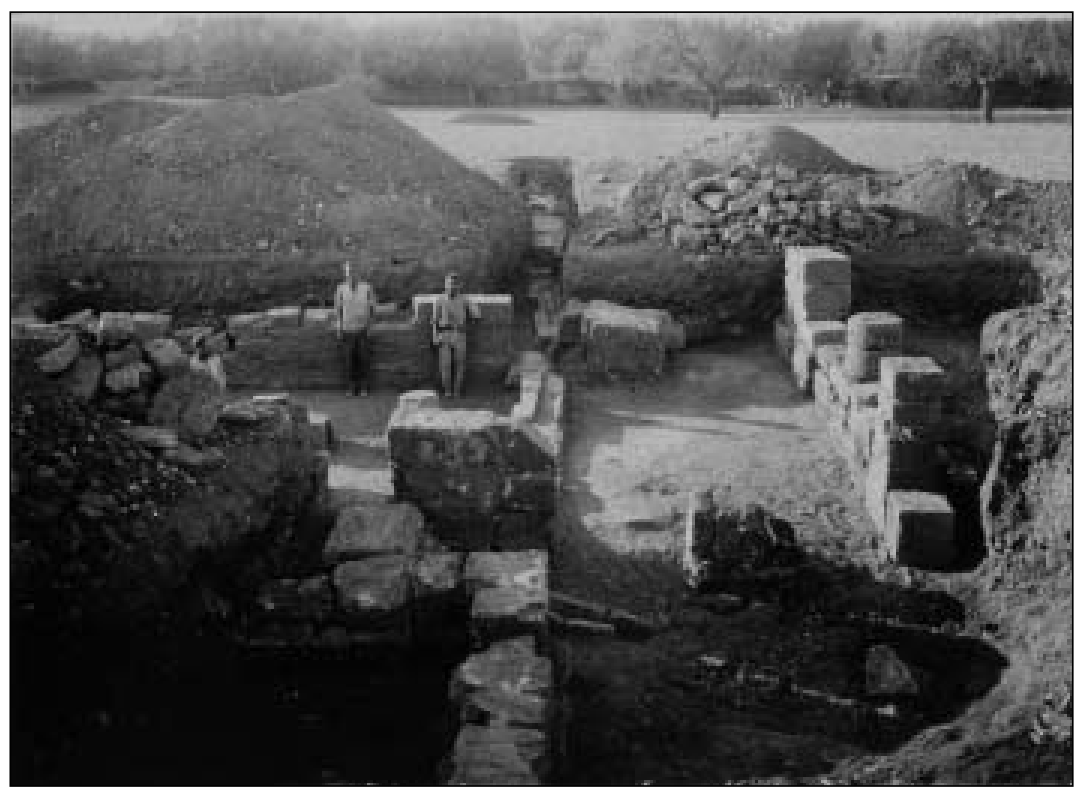

Figura 10. Excavación en la Casa del Colonizador en Santa Anna de Ca'n Costa (1931). Sector E desde el S. Foto: Isasi, s.d.-d. () Museu de Mallorca.

Mientras se trabajaba en la finca de Jaume Ques, se intervino también en dos zonas de la parcela adyacente por el N, Ca'n Basser d'en Tous (Fig. 3). La primera trinchera se abrió inmediatamente al $\mathrm{E}$ de un depósito moderno. Se descubrieron una serie de estancias, con niveles de ocupación de época islámica, por lo que fueron llamadas Casa del Moro (Isasi y Llabrés 1933). Se encontraron, aparte de numerosos fragmentos de cerámica islámica, algunos agujeros con conchas de caracol, que recuerdan a los excavados durante los años 80 en el NW de la Insula 01 en el forum, también fechados en época islámica (Orfila y Riera 2002: 709; Doenges 2005a: 29$30,35)$. En las habitaciones excavadas en la parte W, la gran cantidad de cenizas que aparecieron bajo el pavimento llevó a los excavadores a pensar que la más septentrional habría contado en algún momento con un horno (Isasi y Llabrés 1933).

La otra trinchera practicada en la finca de Ca'n Tous estaba frente a la entrada de la parcela, en su lado W (Figura 3). En este punto, se descubrieron también una serie de habitaciones, algunas de las cuales fueron llamadas Casa del Pintor ${ }^{19}$. En la habitación al SW, encontraron una inscripción fragmentada, el epitafio del pancraciasta Cornelius Atticus ${ }^{20}$, por lo que ésta y las habitaciones contiguas fueron

${ }^{19}$ Ésta no debe confundirse con la antes mencionada Casa del Pintor descubierta en 1923 en la parcela de Ca'n Reinés.

${ }^{20}$ CIBal 30 = Veny 1965: 52-55. Conservada en el Museu de Mallorca, inventario 4.965. llamadas Casa del Pancracio (Isasi y Llabrés 1933; Bosch 1979-1980: 380).

En la campaña del año siguiente (1934), se trabajó simultáneamente en varias zonas de las fincas de Ca'n Pi y de Santa Anna de Ca'n Costa (Fig. 3). La alternancia de las descripciones de los trabajos en los diarios de campo dificultan su correcta interpretación, pero su lectura detenida permite seguir el proceso de excavación. Los mayores problemas son los relacionados con la situación topográfica de las intervenciones en $\mathrm{Ca}$ 'n $\mathrm{Pi}$, ya que no contamos con planos de los trabajos, sino sólo con algunas fotografías y diarios.

A partir del 20 de noviembre se realizaron dos zanjas en Ca'n Pi, una de ellas cerca de la caseta de aperos y del límite con la finca de Santa Anna de Ca'n Costa, a $45 \mathrm{~m}$ de la entrada a la finca por el N (Fig. 3). La otra, por la descripción de los diarios, parece que se situó más al SE, sobre un muro de contención de tierras que separa esta parcela de la de Ca'n Serra (o Tanca d'en Serra) (Fig. 3), aunque no está claro los trabajos que se llevaron a cabo, ya que los hallazgos descritos se refieren casi exclusivamente a la primera trinchera. Los diarios mencionan un pozo, varias habitaciones y una muralla en la trinchera $\mathrm{N}$. Entre los materiales que aparecieron, destacan una mano de bronce ${ }^{21}$ y un friso de 50 x $50 \mathrm{~cm}$ decorado con hojas de acanto. También se excavó el pozo (Bosch 1979-1980: 380), donde se encontró parte de

\footnotetext{
${ }^{21}$ Conservada en el Museu de Mallorca, inventario 4.437.
} 


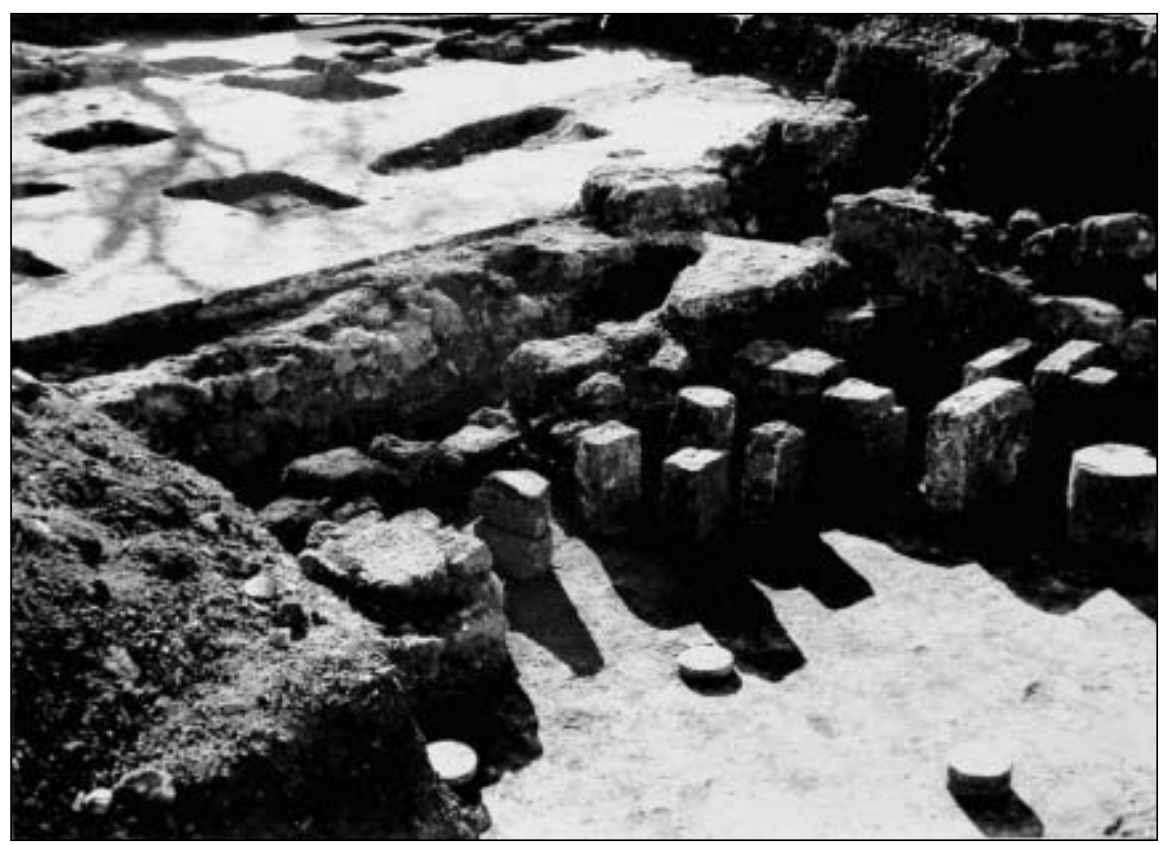

Figura 11. Excavación en Santa Anna de Ca’n Costa, con un presunto hypocaustum (1934). Foto: Isasi, s.d.-c: 79. (C) Museu de Mallorca.

una pierna de mármol de una estatua militar ${ }^{22}$. Cerca del pozo se encontró una muralla con sillares de unos $2 \mathrm{~m}$ de longitud con mortero de cal, en sentido NW-SE (Isasi y Llabrés 1934).

A finales de noviembre se abrió una nueva área de excavación en la era de la finca de Santa Anna de Ca'n Costa (Fig. 3), donde se había hallado en 1923 la Casa del Gobernador, con el objetivo de volver a localizar el suntuoso edificio. El propietario de los terrenos, no obstante, vetó la excavación en la era, de modo que centraron los trabajos al $\mathrm{W}$ de la antigua excavación. Al finalizar la campaña, se habían descubierto una serie de habitaciones, algunas de las cuales (A, B y Z, según el croquis de Ventayol reproducido por Bosch 1979-1980: 381), las más cercanas a la excavación anterior, estaban pavimentadas con mosaicos. Junto a éstas, al W, apareció una gran habitación con opus signinum, con una serie de agujeros cuadrangulares alineados $\mathrm{y}$, hacia el $\mathrm{N}$, una habitación más profunda y una serie de pequeños pilares que llevaron a interpretarlo como un posible hypocaustum de unas termas, posiblemente de carácter privado (Fig. 11) (Orfila y Arribas 2000: 34). Hacia el $\mathrm{N}$ seguían cinco ámbitos más $(\mathrm{E}, \mathrm{D}, \mathrm{F}, \mathrm{G}$, $\mathrm{H})$. En el más septentrional $(\mathrm{H})$ se hallaron tres se-

\footnotetext{
${ }^{22}$ Poco después se descubrió el resto de la estatua reutilizada en los cimientos de un muro. La pieza completa se conserva en el Museu de Mallorca, inventario 21.659.
}

pulturas, con una inscripción funeraria ${ }^{23}$ de fecha tardía (lápida de Arguta) (Fig. 12), interpretadas como cristianas. A raíz de este hallazgo, los mismos directores hablan de una posible basílica cristiana, relacionándola con otras basílicas paleocristianas ya conocidas, como la de Ca's Frares en Santa Maria del Camí (Mallorca). Posteriormente, descartaron esta hipótesis (Isasi y Llabrés 1934).

A principios de 1935 (6-7 de enero), fuera de la campaña oficial de excavaciones, se encontraron por casualidad, en la finca de $\mathrm{Ca}$ 'n $\mathrm{Pi}$, tres estatuas de mármol acéfalas. Habían sido reutilizadas como material de construcción en los cimientos de una muralla, que fue fechada en ese momento en época vándala, y que posiblemente está relacionada con el lienzo hallado unos meses antes en la zona. Las estatuas son una matrona ${ }^{24}$, interpretada recientemente como una gran herculanesa (Veny 2005: 145-148), un togado ${ }^{25}$ y una estatua militar thoraccata $^{26}$ (Isasi y Llabrés 1934; Bosch 1979-1980: 383-384). Se ha

\footnotetext{
${ }^{23}$ Arguta / fidelis in pace / uixit ann(is) XL d(e)p(osita) / III id(us) Iulias (CIBal 55 = Veny 1965, 67-68). Conservada en el Museu de Mallorca, inventario 4.945.

${ }^{24}$ Conservada en el Museu de Mallorca - Museu Monogràfic de Pol-lèntia, inventario 21.661.

${ }_{25}$ Conservada en el Museu de Mallorca - Museu Monogràfic de Pol-lèntia, inventario 21.600.

${ }^{26}$ Conservada en el Museu de Mallorca - Museu Monogràfic de Pol-lèntia, inventario 21.659.
} 


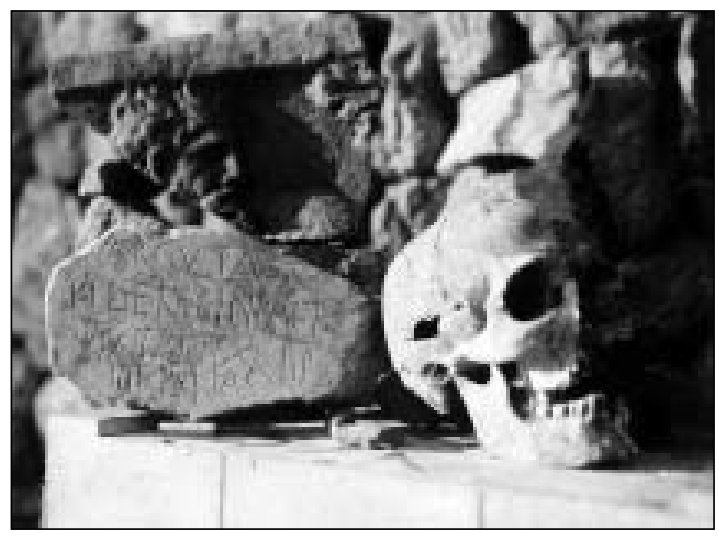

Figura 12. Inscripción y cráneo hallados en la zona de la tumba de Arguta (1935). Foto: Isasi, s.d.-c. (C) Museu de Mallorca.

propuesto que la ubicación original de estas piezas fuera el forum de la ciudad, cuyos restos se encuentran a unos $50 \mathrm{~m}$ de distancia del lugar del hallazgo (Veny 2005: 148-156), aunque también se ha sugerido que decoraran una basílica o unas termas (Moreno 2007: 92-93).

A raíz del éxito de los hallazgos del último año, con varias piezas de escultura, los restos de unas termas con hypocaustum, mosaicos y sepulturas cristianas, se aumentó la subvención para la campaña de 1935 de 5.000 a 10.000 ptas. (Real Academia de la Historia 1935).

La nueva campaña (septiembre-noviembre de 1935) empezó con varias trincheras en la zona de la era de Santa Anna de Ca'n Costa (Fig. 3) (Bosch 1979-1980: 384). La primera de éstas, de cerca de 1 $\mathrm{m}$ de anchura y 41 de longitud, se abrió paralelamente al W de la excavación del año anterior. Apareció un muro orientado N-S, un impluuium - que interpretaron como parte de las termas descubiertas en el año anterior- y varios compartimentos pequeños; alguna de las estancias tenía mosaico blanco y negro. Se abrió también una zanja en sentido E-W, aunque no conocemos su ubicación dentro de la parcela (Isasi y Llabrés 1935). Entre estas trincheras y el camino del cementerio se abrieron dos zanjas más, de las cuales se han conservado croquis de situación y fotografías (Fig. 3). La poca anchura de la zona abierta no permite interpretar ninguna de las estructuras descubiertas (Isasi y Llabrés 1935; Bosch 1979-1980; Isasi s.d.-d). Posteriormente, abrieron una trinchera en sentido E-W que partía de la habitación de la inscripción de Arguta descubierta en la campaña anterior. Se encontró una habitación contigua a la mencionada, con dos sepulturas más. Parece, por los hallazgos que se describen, que esta zanja prosiguió

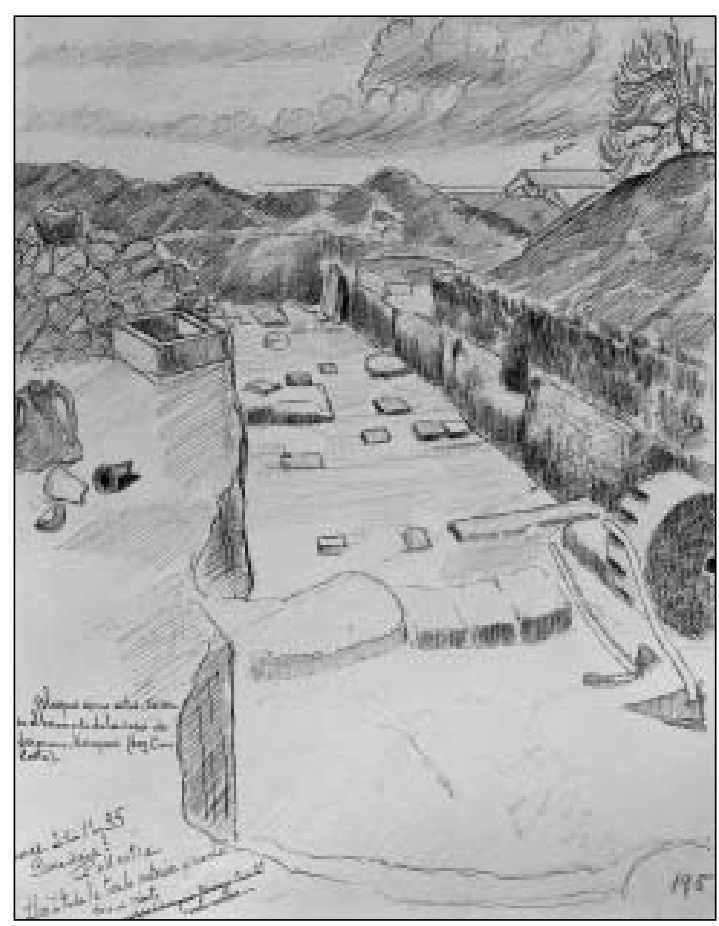

Figura 13. Estructuras encontradas en la trinchera al E de la habitación de Arguta (1935). Dibujo con cámara clara. Foto - Isasi, s.d.c: 279. (C) Museu de Mallorca.

hacia el E, donde descubrieron un muro de grandes bloques en sentido NW-SE, al que se adosaba un horno de pan (Fig. 13). Isasi y Llabrés sugieren que se trate de una muralla. Aparecieron también cerca de 130 monedas en la sala del horno, la mayoría de ellas del siglo Iv (Constantius Clorus, Constantinus, Constantius II, Iulianus) (Isasi y Llabrés 1935).

En el año siguiente, 1936, se consignó una subvención de 5.000 ptas., la misma cantidad de años atrás, pero no se llegó a cobrar nunca (Isasi s.d.-a). De hecho, no disponemos de documentación referente a excavaciones en este año, por lo que es muy probable que no tuvieran lugar. Además, uno de sus directores, Isasi, era militar de profesión, por lo que es posible que tuviera que participar de alguna manera en la Guerra Civil (1936-1939). El conflicto bélico supuso así la paralización de las excavaciones, que no se retomarían, por lo que sabemos, hasta 1942.

\section{LOS AÑOS POSTERIORES A LA GUERRA CIVIL (1942-1946)}

Una vez concluida la Guerra Civil, durante los años 40 Juan Llabrés, pero sobretodo Rafael Isasi, 
continuaron las intervenciones arqueológicas en $\mathrm{Po}$ llentia. Desgraciadamente, la información disponible se vuelve ahora escueta, con sólo algunos croquis y planos de los hallazgos, y breves apuntes del propio Isasi (Isasi s.d.-a; s.d.-b) y de Ventayol, éstos últimos publicados por Bosch (1979-1980).

Antes de estas intervenciones, en 1940, con motivo de la construcción de los urinarios de una escuela cercana (sita en el actual Museu Monogràfic de Pol-lèntia, c/ Sant Jaume, 30 de Alcudia), fue destruida la llamada canal de Ternelles, que atravesaba la muralla de Alcudia a la altura de la iglesia de Sant Jaume y que, una vez dentro del templo, giraba en dirección a Pollentia (Bosch 1979-1980: 385). Esta estructura había sido relacionada con el aprovisionamiento de agua a la ciudad desde la fuente de Ternelles, situada al N de la villa de Pollença (Llabrés 1923; 1924). Desde allí, un acueducto habría transportado el agua de la fuente atravesando la llanura frente a la bahía de Pollença hasta dicho tramo (Furió 1838: 51 52; Reinés y Ferrer 1863: n.1; Llabrés 1924; Binimelis 1927: 158; Arribas, Tarradell y Woods 1973: 24-25; Arribas 1978: 146-147; Cerdá 1978: 27; Cerdà 1993: 23-25; Orfila y Arribas 1997: 63).

Ya en 1940, Juan Llabrés y Rafael Isasi habían solicitado la concesión de 5.000 ptas., que no fueron concedidas, para reanudar las excavaciones ${ }^{27}$.

En 1942 (septiembre-octubre), con una subvención de 5.000 ptas., los trabajos volvieron a la finca de Ca'n Fanals, la misma donde en 1930 se había descubierto parte de una necrópolis y de un edificio (Fig. 3). Excavaron un total de 22 sepulturas con ajuares, una de ellas cerca de la finca adyacente por el N, Ca'n Copido (Isasi s.d.-a). También hallaron parte de los cimientos de un edificio, con una habitación pavimentada con mosaico policromado, estructurado a manera de estrella, con una cruz bizantina en el cuerpo central (Ques 1955; Bosch 1979-1980: 385-386; Isasi s.d.-a). Durante la campaña, según las notas de Isasi, se realizó también una trinchera en la finca de Santa Anna de Ca'n Costa, en sentido E-W, encontrando «algunas ruinas de edificios», sin que contemos con información más explícita (Fig. 3) (Isasi s.d.-a).

En el año siguiente, 1943, la misma subvención de 5.000 ptas. permitió centrar los trabajos en el Camp d'en França (Fig. 3). A partir de esta campaña Juan Llabrés no forma parte de la dirección de las excavaciones por encontrarse fuera de la isla, «desempeñando su destino militar» ${ }^{28}$. La parcela donde

\footnotetext{
${ }^{27}$ Carta de 27/VI/1940 en A.G.A., caja 219, topográfico $12 / / 25$.

${ }^{28}$ Carta de R. Isasi de XI/1943 en A.G.A., caja 217, topográfico $12 / / 25$.
}

tuvo lugar la excavación, según el plano general de Isasi, se encuentra en el cuarto NE de dicha área, propiedad en ese momento de Antoni Torrens «Truyols» (Isasi s.d.-a, s.d.-b). Encontraron los cimientos de un edificio, un horno, un pozo y una habitación con mosaico, así como una inscripción funeraria (Isasi s.d.-a; Bosch 1979-1980: 386).

La campaña de 1944 sólo contó con una subvención de 500 ptas., lo que fue seguramente la razón por que los trabajos duraron sólo unos 15 días del mes de agosto, continuando con los trabajos del año anterior. Se intentó desecar el pozo que había sido descubierto en 1943 en la propiedad de Antoni Torrens, practicando una trinchera a su alrededor. Se abrió también otra zanja donde aparecieron pocos materiales (BSAL 1945, cuya autoría parece ser de Isasi. Manuscrito en Isasi s.d.-b).

Después de estas últimas intervenciones conjuntas (1942-1944), parece que Isasi continuó por su cuenta las excavaciones hasta antes de su muerte en enero de 1948 (Arribas 1983: 37; Isasi s.d.-d). En estos momentos, tuvieron lugar los primeros contactos del mecenas estadounidense William J. Bryant con la arqueología de Pollentia. En 1945, éste se puso en contacto con Jaume Cirera, de la Societat Arqueològica Lul-liana, y Samuel Ventura, maestro de escuela en Alcudia, para que le informaran sobre las posibilidades de excavar en Mallorca. Éstos le remitieron a Rafael Isasi, quien había excavado a lo largo de las últimas décadas en el yacimiento romano de referencia en la isla, la ciudad de Pollentia. Así, el mentor americano le avanzó en 1946 la suma de 20.000 ptas. para la excavación de un trirreme que Isasi decía haber localizado en la bahía de Alcudia. No obstante, parece que el dinero se destinó a la excavación en tierra firme en Pollentia (Isasi s.d.-d). La única referencia con que contamos en relación a la ubicación de los trabajos de este año es una anotación en el plano general de excavaciones realizado por el propio Isasi, que indica que en 1946 se excavó, en el área central del Camp d'en França, algún edificio que se identificó como una supuesta basílica (Fig. 3) (Isasi s.d.-d) en la misma zona que había sido objeto de excavaciones en 1923 y 1926. Por desgracia, no conocemos la existencia de ninguna memoria ni diario de excavación ${ }^{29}$. Isasi murió a principios de 1948, sin remitir informe a su mecenas americano (Doenges 2005b: 19; Orfila 2007: 90).

\footnotetext{
${ }^{29}$ Dada la constancia con que Isasi elaboró los diarios de excavación a lo largo de las campañas desde 1923, resulta extraña esta ausencia de documentación de los trabajos financiados por Bryant. Las posibilidades económicas, sin precedentes, debieron permitir además un gran volumen de trabajo.
} 
Poco después del fallecimiento de Isasi, entre 1948 y 1952, se emprenderían excavaciones desde diferentes instituciones, introduciendo por primera vez criterios estratigráficos en la excavación. Se trataba, pues, no sólo de un cambio en las figuras que trabajaban en Pollentia, sino también en la metodología de los trabajos. Después de algunas intervenciones de Lluís R. Amorós ${ }^{30}$ y Josep Malberti ${ }^{31}$ en sa Portella (1948-1949), de Amorós y Martín Almagro ${ }^{32}$ en la necrópolis de Ca'n Fanals (1949-1950), y de Vicente Ruiz Argilés y Bartomeu Ensenyat en Santa Anna de Ca'n Costa (1950), la William L. Bryant Foundation, creada por William J. Bryant en 1950, se convirtió, a partir de 1951, en la entidad que financiaría las investigaciones hasta 1995/1996 (Doenges 2005b; Orfila 2007: 88-93). Sin embargo, éstas fueron otras etapas de la historia de la investigación arqueológica en uno de los yacimientos romanos de referencia en la arqueología romana hispánica.

\section{CONCLUSIONES}

La muerte de Rafael Isasi ponía fin a la primera etapa de la historia de las intervenciones arqueológicas en Pollentia. Ésta había tenido como protagonistas a reconocidos personajes del mundo erudito, y pertenecientes a las sociedades y academias relacionadas con la cultura, como la Societat Arqueològica Lul-liana, a nivel local, y la Real Academia de la Historia, a nivel estatal. Los trabajos de Gabriel Llabrés, su hijo Juan Llabrés, y Rafael Isasi fueron fruto de un tiempo en que la metodología arqueológica no se había desarrollado y primaban los criterios artísticos sobre los históricos y estratigráficos.

La documentación generada a lo largo de esos trabajos, sin embargo, ha permitido en primer lugar completar la información previamente conocida referente a las campañas de 1923-1927, 1930-1935 y 1942-1946, así como resituar muchas de las intervenciones, las plantas de los edificios a las que hemos podido acceder, e incluso algunos de los materiales más relevantes (Bosch 1979-1980; Merino 1999). Además, hemos podido ampliar notablemente el conocimiento de las campañas de 1942-1946, muy poco documentadas hasta ahora.

En segundo lugar, ha permitido comprobar que el principal objetivo científico que se esbozaba al ini-

\footnotetext{
${ }^{30}$ Comisario Insular de Excavaciones de Mallorca (1948 1951).

${ }^{31}$ Conservador del Museo de Bellver (Palma) (1931-1967).

${ }^{32}$ Director del Museo Arqueológico de Barcelona (19391956).
}

cio de estas intervenciones (Llabrés 1924) fue en gran parte conseguido, ya que se delimitaron varias zonas de la ciudad, así como parte de sus límites (Fig. 3). Se definió una zona de tipo residencial suntuaria ubicada en Santa Anna de Ca'n Costa, un área de necrópolis en Ca'n Fanals y, más al SE, una zona portuaria.

La situación de estas intervenciones sobre la planimetría general permite conocer a priori el nivel de afectación de las diferentes zonas del yacimiento, es decir, el potencial arqueológico que ofrecen, ya sea por lo que respecta a la posible conservación de la estratigrafía, como a las características de las estructuras ya descubiertas entre 1923 y 1946 . En este sentido, los recursos que ofrece el conocimiento fruto de esta investigación son varios ${ }^{33}$. Además, posibilita la contextualización e interpretación de muchos de los hallazgos actuales de trincheras de excavación antiguas.

Los hallazgos en la parcela de Ca'n Reinés permitieron a los investigadores posteriores, ya a inicios de los años 80 del siglo xx, localizar la zona del forum de la ciudad (Arribas 1983: 41-42; Orfila, Arribas y Doenges 2000: 52). De la misma manera, la situación de las excavaciones sobre planimetría actual, y a la vez la situación de algunos de sus materiales singulares en trincheras concretas, cuyo resultado hemos presentado aquí, permitirá en el futuro volver a identificar otros espacios de la ciudad. Las diferentes informaciones que proporcionan Llabrés e Isasi acerca de posibles elementos de muralla en Ca'n Viver (1927) Ca'n Basser (1933), Ca'n Pi (1934) y Santa Anna de Ca'n Costa (1935) son ciertamente sugerentes, frente a los intentos, infructuosos, que se llevaron a cabo en los años 70 para localizar el trazado de la muralla identificada en sa Portella (NW de la ciudad), y dada la proximidad con la fortificación tardía excavada recientemente (Orfila et alii 2000; Riera, Cau y Orfila 2000) en el forum de la ciudad. Asimismo, el hallazgo de una serie de edificios y objetos singulares al $\mathrm{N}$ del forum (campañas de 1923 y 1926) podría estar indicando la existencia en este punto de una zona pública, donde tuvieran cabida un área religiosa (conjunto de tres arce, Figura 7), la sede de algún collegium (estandarte de collegium iuиenum), y un lugar donde exponer unos fas$t i$ (fragmento de fasti), además de varios basamentos de pedestales. El peristilo aparecido en 1931 en Ca'n Pi podría tratarse también, dadas sus grandes

${ }^{33} \mathrm{El}$ proyecto de tesis doctoral de $\mathrm{H}$. Inglada, dirigida por M. Á. Cau, explora la documentación arqueológica antigua de Pollentia para mejorar el conocimiento global de la ciudad. 
dimensiones, de un espacio público o de la palastra de unas termas.

Con la descontextualización de grandes cantidades de materiales, las excavaciones Llabrés-Isasi privaron a la ciencia actual de un conocimiento estratigráfico importante, pero el potencial de la documentación que generaron no debe subestimarse. Su estudio no está ni mucho menos agotado y se ha revelado aquí como una línea de investigación fructífera para el conocimiento de la topografía de la ciudad, que puede ser un punto de referencia a la hora de definir estrategias de excavación. En particular, el período inmediatamente posterior a la Guerra Civil, resulta todavía poco conocido. La investigación de la historiografía es capital en el estudio de cualquier yacimiento, pero adquiere especial relevancia en Pollentia, donde las intervenciones que han tenido lugar alcanzan un volumen muy considerable, ya que los trabajos se han desarrollado desde 1923 hasta la actualidad, con muy pocos periodos de inactividad. Sin duda, aquellos arqueólogos y eruditos anteriores al desarrollo de la disciplina, y que iniciaron la tradición arqueológica en Pollentia hoy hace casi 90 años, tienen todavía algo que enseñarnos.

\section{AGRADECIMIENTOS}

Queremos agradecer la ayuda prestada por parte del personal del Museu de Mallorca a la hora de consultar y obtener copias de esta documentación, al personal del Archivo General de la Administración en Alcalá de Henares y a J.P. Bellón (EEHAR) por la información acerca del fondo de este archivo, así como al personal del Arxiu Municipal de Palma. La imagen en la Fig. 1 ha sido elaborada por Catalina Mas Florit (UB). Agradecemos también a dos evaluadores anómimos cuyos comentarios han contribuido a la mejora de la versión definitiva de este texto. El trabajo de B. Vallori ha sido posible gracias al apoyo del Comissionat per a Universitats i Recerca del Departament d'Innovació, Universitats i Empresa de la Generalitat de Catalunya y del Fondo Social Europeo. Este artículo se ha planteado dentro de las actividades del Equip de Recerca Arqueològica i Arqueomètrica de la Universitat de Barcelona (SGR2009-1173).

\section{BIBLIOGRAFÍA}

Almagro, M. y Amorós, L.R. (1953-54): Excavaciones en la necrópolis romana de can Fanals de
Pollentia (Alcudia, Mallorca). Ampurias. Revista de arqueología, prehistoria y etnología XVXVI: 237-277.

Álvarez Ossorio, F. (1929): Enseña romana de bronce procedente de Pollentia (isla de Mallorca) que se conserva en el Museo Arqueológico Nacional, Madrid.

Amorós, L.R. (1951): Una nueva «tabula patronatus» de Bocchoris. Boletín de la Sociedad Arqueológica Luliana XXX: 632-637.

Amorós, L.R. (1958): El teatro romano de «Pollentia»(Alcudia). Panorama Balear. Imp. Mossèn Alcover, Palma.

Arce, J. (1984): A Roman Bronze Standard from Pollentia (Mallorca) and the Collegia Iuvenum. En: U. Gehring (ed.): Toreutik und figürliche Bronzen römischer Zeit. Akten der 6. Tagung über antike Bronzen. 13. - 17. Mai 1980 in Berlin. Staatliche Museen. Preußischer Kulturbesitz Berlin. Antikenmuseum, Berlin: 33-40.

Arribas, A. (1978): La Arqueología de Pollentia. En: M. Tarradell; A. Arribas; G. Rosselló Bordoy (eds.): Historia de Alcudia. Excmo. Ayuntamiento de Alcudia, Alcudia: 111-291.

Arribas, A. (1983): Pollentia: problemas de topografía y conservación de la ciudad. En: Ayuntamiento de Alcudia (ed.): Symposium de Arqueología. Pollentia y la romanización de las Baleares. XXI centenario de la fundación de Pollentia (Alcudia, julio 1977). Ayuntamiento de Alcudia, Alcudia: 35-46.

Arribas, A.; Orfila, M. y Trias, M.-G. (2000): Introducció general al jaciment. En: M. Orfila (ed.): El Fòrum de Pollentia. Memòria de les campanyes d'excavacions realitzades entre els anys 1996 i 1999. Ajuntament d'Alcúdia. Àrea de Patrimoni, Alcúdia: 17-50.

Arribas, A.; Tarradell, M. y Woods, D.-E. (1973): Pollentia: I. Excavaciones en Sa Portella. Alcudia (Mallorca). Excavaciones Arqueológicas en España 75. Servicio de Publicaciones del Ministerio de Educación y Ciencia. Secretaría General Técnica, Madrid.

Binimelis, J. (1927) [1593]: Nueva historia de la isla de Mallorca y de otras islas a ella adyacentes. Imprenta de José Tous, Palma.

Blanes, C.; Bonet, J.; Font, A. y Rosselló, A. M. (1990): Les illes a les fonts clàssiques. Miquel Font Editor, Mallorca.

Bosch, M. d. C. (1979-1980): Ubi sunt? Mayurqa. De Filosofia i de Ciències de l'Educació 19: 375-387.

BSAL (1940): Las excavaciones de «Pollentia». Sección oficial de noticias, Boletín de la Sociedad Arqueológica Luliana XXVIII: 187. 
BSAL (1945): Excavaciones en «Pollentia» en 1944. Sección oficial y de noticias, Boletín de la Sociedad Arqueológica Luliana XXIX: 292.

Casado, D. (2006): El entorno historiográfico español entre el último cuarto del XIX y el primer tercio del XX, a través de la mirada de Gabriel Llabrés y José Ramón Mélida. Mayurqa. Revista del Departament de Ciències Històriques i Teoria de les Arts 31: 341-357.

Cau, M.-Á.; Orfila, M. y Mas, C. (2008): Les evidències de producció ceràmica a Mallorca en època romana. En: M. Á. Cau (ed.): Estudi arqueològic i caracterització arqueomètrica de la ceràmica comuna romana del forn de sa Mesquida (Calvià, Mallorca). El Tall Editorial, Mallorca: 21-27.

Cerdá, D. (1978): Economia antigua de Mallorca. En: J. Mascaró Pasarius (ed.): Historia de Mallorca II. Vicente Colom Rosselló, Palma de Mallorca: 1-32.

Cerdà, D. (1993): De l'època obscura de Pollença. De la «Pax Romana». Cala Murta. Bolletí de la «Fundació Rotger-Villalonga» 14: 8-29.

Chávez, E.; Orfila, M. y Mancilla, M. I. (2000a): Habitació A. Illeta de tabernae a l'oest del fòrum. Quadres F-17, F-18, E-17 i E-18. En: M. Orfila (ed.): El fòrum de Pollentia. Memòria de les campanyes d'excavacions realitzades entre els anys 1996 i 1999. Ajuntament d'Alcúdia. Àrea de Patrimoni, Alcúdia: 77-82.

Chávez, E.; Orfila, M. y Mancilla, M. I. (2000b): Habitació B. La illa de tabernae a l'oest del fòrum. Quadres E-17, E-18, E-19, F-17, F-18 i F-19. En: M. Orfila (ed.): El fòrum de Pollentia. Memòria de les campanyes d'excavacions realitzades entre els anys 1996 i 1999. Ajuntament d'Alcúdia. Àrea de Patrimoni, Alcúdia: 83-89.

Dameto, J. (1632): La Historia General del Reino Baleárico. Gabriel Guasp, Mallorca.

Díaz-Andreu, M. y Ramírez Sánchez, M.E. (2001): La Comisaría General de Excavaciones Arqueológicas (1939-1955). La administración del patrimonio arqueológico en España durante la primera etapa de la dictadura franquista. Complutum 12 : 325-344.

Doenges, N.A. (2005a): Pollentia. A Roman Colony on the Island of Mallorca. BAR International Series 1404. Archaeopress. Publishers of British Archaeological Reports, Oxford.

Doenges, N.A. (2005b): The William L. Bryant Foundation. A Brief History. Dartmouth College, Hanover, New Hampshire.

Domínguez, J. (1989): Gabriel Llabrés y Quintana y la Revista de Huesca (1903-1905). Alazet. Revista de Filología 1: 29-48.
Equip d'excavació de Pollentia (1993): Un conjunt de materials d'època tardo-republicana de la ciutat romana de Pollentia (Alcúdia, Mallorca). Pyrenae 24: 227-267.

Equip Pollentia (1994): Resultats dels treballs d'excavació a l'àrea central de la ciutat romana de Pollentia (Alcúdia, Mallorca): avanç preliminar. Pyrenae 25: 215-224.

Furió, A. (1838): Carta histórico-crítica sobre el lugar donde estuvo situada la antigua Pollentia en la época que los romanos dominarion la isla de Mallorca. Imprenta nacional regentada por D. Juan Guasp y Pascual, Palma.

Gumà, M. M.; Riera, M. M. y Torres, F. (1998): Contextos ceràmics dels segles IV-X a l'illa de Mallorca. En: Comes, M.; Gurt, J.M.; López, A.; Padrós, P.; Roca, M. (eds.): Contextos ceràmics d'època romana tardana $i$ de l'alta edat mitjana (segles IV-X). Actes. Taula Rodona. Badalona 6, 7 i 8 de novembre de 1996. Arqueomediterrània 2. Àrea d'Arqueologia - Universitat de Barcelona, Barcelona: 249-268.

Hübner, E. (1888): Monumentos epigráficos de las islas Baleares. Boletín de la Real Academia de la Historia XIII, V: 465-477.

Isasi, R. (s.d.-a): Excavaciones 1930, 1931, 1933, 1934, 1935. Cuadernos de Notas de Campo. Manuscrito conservado en: Biblioteca del Museu de Mallorca, NIG 27631.

Isasi, R. (s.d.-b): Excavaciones en Pollentia en 1944. Manuscrito conservado en: Biblioteca del Museu de Mallorca, NIG 27633.

Isasi, R. (s.d.-c): Excavaciones Pollentia 1933, 1934, 1935. Manuscrito conservado en: Biblioteca del Museu de Mallorca, NIG 27630.

Isasi, R. (s.d.-d): Mallorca romana. «Pollentia». Notas de excavaciones desde 1923 hasta 1931 inclusive. Manuscrito conservado en: Biblioteca del Museu de Mallorca, NIG 27629.

Isasi, R. (s.d.-e): Pollentia. Manuscrito conservado en: Biblioteca del Museu de Mallorca, NIG 27034.

Isasi, R. y Llabrés, J. (1933): Dietario de los trabajos de la campaña de 1933. En: Mallorca romana. «Pollentia». Notas de excavaciones desde 1923 hasta 1931 inclusive. Manuscrito conservado en: Biblioteca del Museu de Mallorca, NIG 27629.

Isasi, R. y Llabrés, J. (1934): Excavaciones en la antigua Pol.lentia. Año 1934. Dietario. En: $M a$ llorca romana. «Pollentia». Notas de excavaciones desde 1923 hasta 1931 inclusive. Manuscrito conservado en: Biblioteca del Museu de Mallorca, NIG 27629.

Isasi, R. y Llabrés, J. (1935): Excavaciones del año 
1935. En: Mallorca romana. «Pollentia». Notas de excavaciones desde 1923 hasta 1931 inclusive. Manuscrito conservado en: Biblioteca del Museu de Mallorca, NIG 27629.

Llabrés, G. (1923): 1923. La Ciudad romana de POLLENTIA y las excavaciones arqueológicas en Alcudia. En: R. Isasi (s.d.-d): Mallorca romana. «Pollentia». Notas de excavaciones desde 1923 hasta 1931 inclusive. Manuscrito conservado en: Biblioteca del Museu de Mallorca, NIG 27629.

Llabrés, G. (1924): En las entrañas de la tierra. La ciudad romana de Pollentia y las excavaciones arqueológicas en Alcudia. Majórica 1.

Llabrés, J. e Isasi, R. (1934): Excavaciones en los terrenos donde estuvo enclavada la ciudad romana de «Pollentia» (Baleares, isla de Mallorca, término municipal de Alcudia). Memoria de los trabajos practicados en 1930-1931. Junta Superior del Tesoro Artístico. Sección de Excavaciones, Madrid.

Martorell y Peña, F. (1879): Apuntes arqueológicos, Barcelona.

Mascaró Pasarius, J. (1968): Prehistoria de las Balears. Gráficas Miramar, Palma de Mallorca.

Mayer, M. (2005): Les Illes Balears i llur reflex a les fonts literàries i epigràfiques. Revisió d'alguns aspectes. En: M. L. Sánchez León y M. Barceló (eds.): XXIII Jornades d'Estudis Històrics Locals. L'Antiguitat clàssica i la seva pervivència a les illes Balears. Palma, del 17 al 19 de novembre de 2004. Institut d'Estudis Baleàrics, Palma: 39-60.

Mayer, M. (2008): Carthago capta: la fecha de la toma de Cartago por los romanos. Mélanges de l'École Française de Rome, Antiquité 120/1: 93-97.

Merino, J. (1995): La sortida de materials arqueològics de Pollentia envers el Museo Arqueológico Nacional. En: G. Roselló Bordoy (ed.): Actes del III Congrés. El nostre patrimoni cultural: el patrimoni tudat (1836-1994). Societat Arqueològica Lul-liana, Mallorca: 39-50.

Merino, J. (1997): Arqueología y conservación del Patrimonio Histórico en la Mallorca de la Restauración. En: G. Mora y M. Díaz-Andreu (eds.): La Cristalización del pasado: génesis y desarrollo del marco institucional de la arqueología en España. Servicio de Publicaciones de la Universidad de Málaga. Ministerio de Educación y Ciencia, Málaga: 369-379.

Merino, J. (1999): Les excavacions arqueològiques de Gabriel Llabrés Quintana a Pol.lèntia (1923, 1926 i 1927). I Jornades d'Estudis Locals d'Alcúdia. 13 i 14 de novembre de 1998. Ajuntament d'Alcúdia, Alcudia: 39-50.
Moragues, M. y Bover, J. M. (eds.) (1841): Historia General del Reino de Mallorca escrita por los cronistas Don Juan Dameto, Don Vicente Mut y Don Gerónimo Alemany II. Imprenta nacional a cargo de D. Juan Guasp y Pascual, Palma.

Moreno, S. (2007): Contexto y funcionalidad de las representaciones escultóricas pétreas de Pollentia. Arqueología y Territorio 4: 87-106.

Nielsen, I. (1990): Thermae et Balnea. The architecture and cultural history of roman public baths. Aarhus University Press, Aarhus.

Orfila, M. (ed.) (2000): El fòrum de Pollentia. Memòria de les campanyes d'excavacions realitzades ente els anys 1996 i 1999. Ajuntament d'Alcúdia. Àrea de Patrimoni, Alcúdia.

Orfila, M. (2007): Una visión general de la ciudad romana de Pollentia. Época tardo-republicana y alto imperial. En: Mallorca romana. Asociación Amigos del Castillo de San Carlos «Aula General Weyler», Palma: 87-141.

Orfila, M. y Arribas, A. (1997): La ciudad romana de Pollentia (Alcudia, Mallorca) en la actualidad. En: A. Navareño; P. Mateos; F. Lavado (ed.): Congreso ciudades históricas vivas. Ciudades del pasado: pervivencia y desarrollo I. Editora Regional de Extremadura: 63-67.

Orfila, M. y Arribas, A. (2000): Pollentia a través de l'arqueologia. En: M. Orfila (ed.): El fòrum de Pollentia. Memòria de les campanyes d'excavacions realitzades ente els anys 1996 i 1999. Ajuntament d'Alcúdia. Àrea de Patrimoni, Alcúdia: 33-50.

Orfila, M.; Arribas, A. y Cau, M. A. (1999): La ciudad romana de Pollentia: el foro. Archivo Español de Arqueología 72: 99-118.

Orfila, M.; Arribas, A. y Doenges, N. A. (2000): Resultat de les investigacions arqueològiques realitzades sobre el forum entre 1980 i 1995 . En: M. Orfila (ed.): El fòrum de Pollentia. Memòria de les campanyes d'excavacions realitzades ente els anys 1996 i 1999. Ajuntament d'Alcúdia. Àrea de Patrimoni, Alcúdia: 51-64.

Orfila, M.; Chávez, M.E. y Cau, M. Á. (2008): El programa figurativo de la ciudad romana de $P O$ llentia (Alcudia, Mallorca, España). En: E. La Rocca, P. León, C. Parisi Pressice (eds.): Le due patrie acquisite. Studi di archeologia dedicati a Walter Trillmich. «L'Erma» di Bretschneider, Roma: 325-332.

Orfila, M. y Riera, M. (2002): Alguns vestigis d'època islàmica al fòrum de Pollentia. En: Homenatge a Guillem Rosselló Bordoy. Govern de les Illes Balears, Conselleria d'Educació i Cultura. Direcció General de Cultura, Palma: 705-724. 
Orfila, M.; Riera, M.; Cau, M. Á. y Arribas, A. (2000): Aproximación a la topografia urbana tardía de Pollentia (Mallorca): construcciones defensivas. En: J. M. Gurt y N. Tena (eds.): V Reunió d'Arqueologia Cristiana Hispànica. Cartagena, 16-19 d'abril de 1998. Institut d'Estudis catalans, Secció Històrico-Arqueològica. Universidad de Murcia, Área de Arqueología. Universitat de Barcelona, Departament de Prehistòria, Història Antiga i Arqueologia. Universitat Autònoma de Barcelona, Departament de Ciències de l'Antiguitat i de l'Edat Mitjana. Museo Arqueológico de Cartagena: 229-235.

Peiró, I. y Pasamar, G. (1996): La Escuela Superior de Diplomática (los archiveros en la historiografía española contemporánea). Anabad, Madrid.

Peiró, I. (1992): El mundo erudito de Gabriel Llabrés y Quintana. Ajuntament de Palma. Servei d'Arxius i Biblioteques. Biblioteca Gabriel Llabrés, Palma.

Perea, S. (1997): El genio encapuchado de Pollentia, en el M.A.N., y el Telesforo, el dios-médico de Pérgamo. Boletín del Museo Arqueológico Nacional XV,1 y 2: 129-134.

Pons, J. (1948): Necrología. D. Rafael Isasi. Boletín de la Sociedad Arqueológica Luliana XXX: 349350.

Pons, J. (1975): Necrología. Juan Llabrés. Boletín de la Sociedad Arqueológica Luliana XXXIV: 591596.

Pozo, S.F. (1989): Bronces romanos de Pollentia conservados en el M.A.N. de Madrid. Boletín del Museo Arqueológico Nacional VII, 1 y 2: 67-83.

Ques, J. (1955): La «Pollentia Cristiana» y la cueva de San Martín. Diario de Mallorca. La Almudaina, 30-I-1955, año III, no 459.

Real Academia de la Historia (1935): Expediente sobre las excavaciones en Pollentia. Manuscrito conservado en el Archivo-Biblioteca de la Real Academia de la Historia, Signatura CAIB/9/7945/ 37(1).

Reinés y Ferrer, J. (1863): Destrucción de Pollentia. Antigua capital de Mallorca, y sitio que tuvo durante la dominación romana. Imprenta de $\mathrm{Pe}$ dro José Gelabert, Palma.

Riera, M.; Cau, M. A. y Orfila, M. (2000): El recinte fortificat. Quadres: K11, K12, K13, K14, K15,
K16, K17, K18, K19, J11, J12, J13, J14, J15, J16, J17, J18, J19, L14 i L15. En: M. Orfila (ed.): El fòrum de Pollentia. Memòria de les campanyes d'excavacions realitzades ente els anys 1996 i 1999. Ajuntament d'Alcúdia. Àrea de Patrimoni, Alcúdia: 123-130.

Rosselló Bordoy, G. (1971): Homenaje al investigador Rafael de Ysasi. Mayurqa. Miscelánea de Estudios Humanísticos 6: 87-92.

Rosselló Bordoy, G. y Merino, J. (2005): El patrimoni de les Illes Balears romanes: història de les investigacions, les troballes i les col-leccions. En: F. Turoges (ed.): El món romà a les Illes Balears. Fundació «la Caixa», Barcelona: 145-153.

Sans, E. (1929): Rectificació a l'obra «Historia de Alcudia» de D. Pere Ventayol i Suau. Bolletí de la Societat Arqueològica Lul-liana XXII: 354355.

Serra y Ferragut, B. (1766): Disertación histórica sobre una inscripción romana del pueblo bocchoritano, hallada en Mallorca en el territorio de la Villa de Pollença en el Año de 1765. Imprenta de Antonio Guasp, Mallorca.

Tarradell, M. (1978): Pollentia. Esquema de una aproximación histórica. En: M. Tarradell, A. Arribas y M. Roselló Bordoy (eds.): Historia de Alcudia. Excmo. Ayuntamiento de Alcudia, Alcudia: 293-357.

Vallori, B. y Cau, M.Á. (próxima aparición): Pollentia 1593-1923. La recerca d'una ciutat de les fonts clàssiques.

Ventayol, P. (1927): Historia de la Muy Noble, Leal, Ilustre, Invicta, etc. Ciudad Fidelísima de Alcudia. Desde los tiempos prehistóricos hasta nuestros días I. Biblioteca de la Ultima Hora, Palma de Mallorca.

Veny, C. (1965): Corpus de las inscripciones baleáricas hasta la dominación árabe. Consejo Superior de Investigaciones Científicas. Delegación de Roma, Roma.

Veny, C. (2005): Las cinco grandes esculturas de la Pollentia romana balear. En: M. L. Sánchez León y María Barceló (eds.): XXIII Jornades d'Estudis Històrics Locals. L'Antiguitat clàssica i la seva pervivència a les illes Balears. Palma, del 17 al 19 de novembre de 2004. Institut d'Estudis Baleàrics, Palma: 137-160. 